\title{
New-Onset Atrial Fibrillation in Adult Patients After Cardiac Surgery
}

\author{
Peter S. Burrage ${ }^{1} \cdot$ Ying H. Low ${ }^{1} \cdot$ Niall G. Campbell ${ }^{2} \cdot$ Ben O'Brien $^{3,4}$
}

Published online: 24 April 2019

(C) The Author(s) 2019

\begin{abstract}
Purpose of Review An overview of recent literature regarding pathophysiology, risk factors, prophylaxis, and treatment of newonset atrial fibrillation (AF) in post-cardiac surgical patients.

Recent Findings $\mathrm{AF}$ is the most frequent adverse event after cardiac surgery with significant associated morbidity, mortality, and financial cost. Its causes are multifactorial, and models to stratify patients into risk categories are progressing but a consistent, evidence-based system has not yet been developed. Pharmacologic and surgical interventions to prevent and treat this complication have been an area of ongoing research and recent societal guidelines reflect this.

Summary Inconsistencies remain surrounding how to best identify higher-risk AF patients, which interventions should be used to prevent and treat AF, and which patient groups should receive these interventions. The evidence for these available strategies and their place in contemporary guidelines are summarized.
\end{abstract}

Keywords Atrial fibrillation $\cdot$ Cardiac surgery $\cdot$ Adult $\cdot$ Risk factors $\cdot$ Prevention $\cdot$ Treatment

\section{Introduction}

Atrial fibrillation after cardiac surgery (AFACS) is the most common postoperative complication following cardiac surgical procedures and occurs in $25 \%$ after isolated coronary artery bypass grafting (CABG), $30 \%$ after isolated valvular procedures, and

Peter S. Burrage and Ying H. Low contributed equally to this work.

This article is part of the Topical Collection on Critical Care Anesthesia

Ben O'Brien

ben.obrien@bartshealth.nhs.uk

Peter S. Burrage

peter.s.burrage@ hitchcock.org

Ying H. Low

ying.h.low@hitchcock.org

Niall G. Campbell

n.campbell@ doctors.org.uk

1 Department of Anesthesiology, Dartmouth-Hitchcock Medical Center, Lebanon, NH 03756, USA

2 Department of Cardiology, Wythenshawe Hospital, Manchester, UK

3 William Harvey Research Institute, Queen Mary University of London, St Bartholomew's Hospital, London, UK

4 Outcomes Research Consortium, Cleveland Clinic, Cleveland, $\mathrm{OH}$, USA
40-50\% following combination CABG/valvular operations [1]. Notably, the incidence of AFACS has remained largely unchanged despite contemporaneous improvements in cardiac surgery-associated morbidity and mortality $[2,3]$.

While postoperative atrial fibrillation (POAF) is not a problem unique to cardiac surgical patients, rates of AFACS are significantly higher than those in both thoracic surgery (10 $30 \%)$ and non-cardiac, non-thoracic surgery $(1-15 \%)[4,5]$. Additionally, AFACS has different characteristics when compared to POAF following non-cardiac surgery including potential mechanisms and data supporting measures for prevention and treatment.

While AFACS may have once been considered a transient and predominantly benign complication, its associations with increased morbidity such as postoperative stroke, sternal and respiratory tract infections, and gastrointestinal dysfunction and renal dysfunction as well as increased short- and longterm mortality are now well-established [6-9]. The onset of AFACS has also been correlated with longer, and costlier, lengths of stay (LOS) in the intensive care unit and hospital, in addition to increased rates of readmission [7, 10-12]. These outcomes translate into a substantial financial impact; approximately $\$ 2$ billion annually has been attributed to AFACS care specifically [13], out of a total annual expenditure related to $\mathrm{AF}$ care in the USA of more than $\$ 6$ billion, [13-16]. It is uncertain to what extent these relationships are causal. 
Taking into account the considerable effect that improvements in AFACS care could have on both patient outcomes and financial healthcare burdens, substantial research efforts have been directed at identifying the mechanisms behind AFACS as well as effective prophylactic and treatment strategies for this adverse postoperative event. The goal of the review article is to highlight the current understanding regarding AFACS pathogenesis, risk factors, prophylaxis, and treatment. To this end, on October 17, 2018, the following search operations were performed in PubMed: ((("Cardiac Surgical Procedures"[Mesh] OR cardiac surg*[ti] OR after cardiac surgery[tiab] OR coronary artery bypass[ti] OR cabg[ti] OR coronary artery surgery[ti] OR heart valve*[ti] OR mitral valve*[ti] OR aortic valve*[ti]) AND ("Atrial Fibrillation"[Mesh] OR afib[ti] OR "a fib"[ti] OR Atrial Fibrillation*[ti] OR “AF”[ti]) AND (etiology OR postoperative OR new onset[tiab])) NOT ("Comment" [Publication Type] OR "Letter" [Publication Type] OR "Editorial" [Publication Type]) AND (“2015/10/17”[PDat] : “2018/10/ 17'[PDat] AND English[lang])) and relevant publications were identified.

\section{AF Pathophysiology and Mechanisms}

AF is a supraventricular arrhythmia characterized by erratic atrial depolarizations leading to disorganized, ineffective atrial contractions, and variable atrioventricular nodal conduction, which results in an irregular ventricular rate [17]. An expert consensus document defined the diagnosis of $\mathrm{AF}$ as requiring a 12-lead electrocardiogram (ECG) or a rhythm strip of at least 30-s duration that demonstrates (1) irregular RR intervals in the absence of complete AV block, (2) an absence of distinct $\mathrm{P}$ waves on surface ECG, and (3) an atrial cycle length that is variable and generally less than $200 \mathrm{~ms}$ [18].

It is unlikely that there is a single unifying mechanism behind the development of AF, but it is generally agreed that $\mathrm{AF}$ requires both a trigger and a susceptible atrial substrate that allows for maintenance of the arrhythmia [19, 20]. Most commonly, this trigger impulse is thought to arise from the myocardial sleeves of the left atrium that blend into the approaching pulmonary veins [21]. Histologically, this area is remarkable for a relatively unique myocardial fiber structure that has areas of discontinuity and fibrosis. This particular tissue architecture may be responsible for the electrophysiologic properties conducive to the generation of frequent ectopic foci that can act as a trigger for AF initiation [21]. Notably, there are multiple ganglionated autonomic nerve plexuses that are associated with these left atrium/pulmonary vein junctions which provide an anatomical basis for the development of spontaneous ectopic foci by variations in sympathetic and parasympathetic tone [22]. Interestingly, an episode of atrial fibrillation lasting only hours to weeks can lead to electrophysiological remodeling mediated by alterations in function of several ion channels, most commonly those responsible for calcium and potassium fluxes. A duration of months or longer can then lead to progressive structural remodeling of the atrium itself, heralded by progressive fibrosis, dilation, and hypertrophy. Together, these changes can act in a feed-forward manner to further promote a pro-arrhythmic substrate [23, 24].

Patient factors, cardiac surgical factors, and endogenous/ exogenous postoperative factors may align to specifically predispose patients presenting to the cardiac surgical operating room for developing AFACS. Patients requiring cardiac surgery frequently have pre-existing risk factors for atrial dilation including hypertension, myocardial ischemia, and valvular abnormalities such as mitral regurgitation. Perioperatively, direct surgical trauma associated with atriotomy incisions and pericardial disruption may also contribute to local inflammation and subsequent alterations in atrial electrical excitability. It has also been observed that while on cardiopulmonary bypass, the atria can remain electrically active despite sufficient cardioplegia administration for ventricular electrical arrest. This continuing activity may predispose the atria to ischemia and subsequent arrhythmias [25]. Large fluid shifts perioperatively and electrolyte disturbances may also be contributory [13]. In the postoperative period, the patient may be exposed to a number of proarrhythmogenic factors, including increased endogenous catecholamines, inflammatory and oxidative mediators secondary to surgical stress and the systemic response to cardiopulmonary bypass, use of exogenous catecholamines for inotropic support, and variations in both intravascular volume status and systemic blood pressure leading to changes in atrial stretch and myocardial perfusion, respectively.

Two separate phases regarding the risk of development of AFACS, with distinct associated factors, have been described. The first phase encompasses the first $18 \mathrm{~h}$ postoperatively with the greatest risk at hour zero, and the second phase occurs with the risk peaking at 24-48 hrs [26]. This observation raises the possibility that separate mechanisms may be responsible for AFACS development within each phase.

\section{Risk Factors for AFACS}

Different series have reported a number of risk factors for the development of AFACS including a prior history of paroxysmal AF, obesity, chronic obstructive pulmonary disease, chronic renal failure, rheumatic heart disease, and male gender, as well as echocardiographic predictors such as abnormal left ventricular systolic and diastolic function, left ventricular hypertrophy, and increased left atrial volume. The most consistent independent risk factor across multiple studies has been increasing patient age [7, 13, 27-45]. A number of scoring 
systems have been generated to predict the risk of developing AFACS with the goal of being able to preoperatively identify high-risk patients to allow for use of appropriately targeted prophylactic regimens as recommended by a number of societal guidelines [7, 31-45]. Furthermore, to date, consistent reproducibility of factors between studies has been lacking and a post hoc validation analysis utilizing three risk scores derived from some of the largest trials obtained a low predictive value for these scores when applied prospectively to a patient cohort [46]. It remains speculative whether the identification of a higher risk AF population could ultimately translate to improve patient outcomes, although AFACS rates, and associated increases in length of stay and cost, might as well be reducible with targeted aggressive prevention.

There is significant heterogeneity in the literature regarding how POAF is defined, identified, and reported. Some studies use opportunistic identification of AF (typically retrospective studies) whereas others utilize continuous monitoring that is more likely to identify asymptomatic AF and results in a higher reported incidence. This heterogeneity can make a direct comparison between studies problematic. We would advise that all future prospective studies reporting the incidence of POAF should supplement routine in-patient heart rhythm monitoring with a 5-day continuous Holter recording, allowing the independent confirmation of the diagnosis of AF.

While a number of societies have released guidelines regarding prophylactic strategies for AFACS in high-risk patients, there is not currently a consistent, evidence-based system for the stratification of patients into different risk groups. In this context, the Society of Cardiovascular Anesthesiologists (SCA) and the European Association of Cardiothoracic Anaesthesiologists (EACTA) Clinical Practice Improvement Group for AF after Cardiac Surgery recently published a comprehensive practice advisory, in which they also created a list of AFACS risk factors and prophylactic strategies using expert opinion, based on published risk score models for AFACS. These risk factors and prophylactic and therapeutic strategies have been summarized in a graphical advisory tool (Figure 1) $[47 \bullet \bullet, 48 \bullet \bullet$ and may enable improved adherence to evidence-based recommendations.

\section{Preventative Strategies and Associated Evidence Base}

Many different pharmacologic agents and surgical strategies have been studied for preventing the development of AFACS. Strategies using medical-based interventions have focused on several general areas including optimization of electrolytes, prophylactic use of antiarrhythmic medications, reduction of both systemic and localized inflammation, moderating autonomic influences, reduction of oxidative stress secondary to surgery, and choice of vasoactive medication. Surgical-based therapies that have been investigated have included the use of exogenous pacing, modifications to juxtaposed anatomic structures including the pericardium and the anterior fat pad, addition of a concurrent ablation procedure, and the effect of an on-pump vs off-pump surgical approach. These prophylactic strategies and the associated strength of society recommendation, when available, are summarized in Table 1.

\section{Pharmacological Strategies}

\section{Electrolyte Management}

Magnesium Low serum magnesium levels are a predictor for AFACS [112, 113], and hypomagnesemia is common in postcardiac surgical patients $[114,115]$. The effect of magnesium may be attenuated in patients on concomitant beta-blockers $[52,114]$. Another consequence of hypomagnesemia is a diminished response to potassium supplementation [116]. A 2013 meta-analysis included 21 studies $(n=2988)$ investigating various dose regimens of intraoperative intravenous magnesium administration on AFACS and supraventricular tachycardia, and it found a significant reduction in postoperative atrial fibrillation in the magnesium group compared to controls $\left(16.5 \%\right.$ vs $26.2 \%$, OR $0.55,95 \%$ CI $\left.0.41-0.73, I^{2}=51 \%\right)$ [49••]. Careful magnesium repletion is a generally safe practice in patients with hypomagnesaemia and should be considered in all patients without severe renal dysfunction.

Potassium Potassium is also frequently depleted amongst cardiac surgical patients who do not receive supplementation, and hypokalemia has been identified as a risk factor for AFACS, particularly if serum potassium is below the normal range $[49,50,116,117]$. Practice surveys reveal that it appears to be routine practice in many centers to target serum potassium levels at the upper end of the normal range $(4.5-5.5 \mathrm{mEq} /$ L) $[50,51]$. However, there is no definitive evidence of its AFACS prophylactic efficacy or impact on clinical outcomes [49••, 50]. A 2016 prospective double-blinded interventional study of 910 cardiac surgical patients who were randomized to a potassium target of $4.0 \mathrm{mmol} / \mathrm{L}$ or $4.5 \mathrm{mmol} / \mathrm{L}$ using a computer algorithm found no difference in AFACS [118]. The Tight $\mathrm{K}$ trial is an ongoing randomized controlled trial (RCT) to examine AFACS in patients randomized to relaxed $(\geq 3.6 \mathrm{mEq} / \mathrm{LL}$ ) vs tight $(\geq 4.5 \mathrm{mEq} / \mathrm{L})$ control of serum potassium [50]. Potassium should be supplemented in patients with hypokalemia, but the additional utility of maintaining a high-normal potassium to prevent $\mathrm{AF}$ is currently unproven.

\section{Antiarrhythmic Drugs}

Beta-adrenergic blockers Beta-blockers have been extensively studied for the prevention of AF after cardiac surgery, and their likely mechanism is a decrease in sympathetic tone, 


\section{Preventing Perioperative AF in Cardiac Surgical Patients}

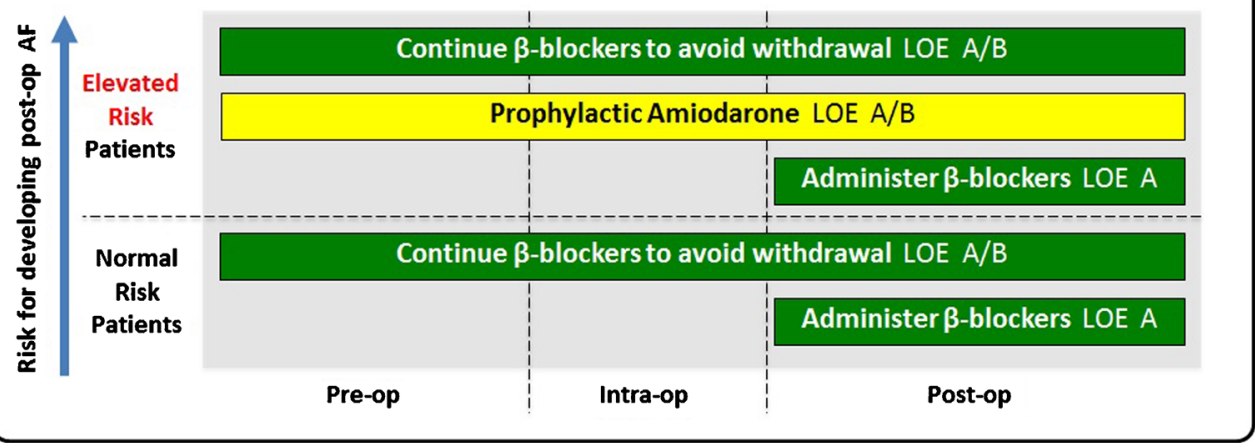

\section{Treating Perioperative AF in Cardiac Surgical Patients}

Nondihydropyridine CCB or $\beta$-blocker for rate control LOE B

Electrical or chemical (e.g. - amiodarone) cardioversion if hemodynamic instability LOE B

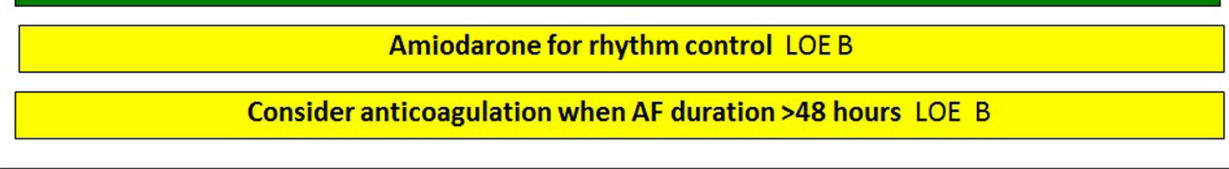

Additional Therapies with only Class Ilb Recommendation
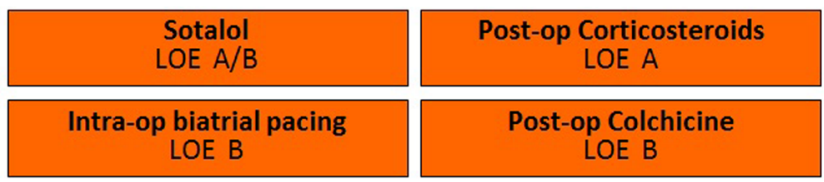

Fig. 1. SCA/EACTA Graphical Practice Advisory for the management of AFACS, summarizing evidence-based prevention and treatment strategies and risk factors for perioperative atrial fibrillation in cardiac surgical patients. Reproduced from Muehlschlegel JD, Burrage PS, Ngai JY, Prutkin JM, Huang CC, Xu X et al. Society of Cardiovascular Anesthesiologists/European Association of Cardiothoracic Anaesthetists

which increases atrial refractoriness and decreases the initiation of arrhythmias [113, 114, 119]. A 2013 meta-analysis of 33 RCTs $(n=4698)$ found that preoperative treatment with beta-blockers resulted in a significant reduction in AFACS (16.3\% vs $31.7 \%$, OR $0.33,95 \%$ CI $\left.0.26-0.43, I^{2}=55 \%\right)$ [49]. In addition, many patients in the control groups stopped non-study beta-blockers to participate in the study and some authors have suggested that this withdrawal may be an independent risk factor for AFACS [7, 114]. A meta-analysis in 2006 compared studies that withdrew non-study betablockers, against those that continued non-study betablockers; while both groups found significant reductions in AFACS with their treatment groups, the group that withdrew beta-blockers demonstrated larger effects between groups [52, 114]. Other studies have examined the effects of different types of beta-blockers on AFACS. It has been reported that oral metoprolol is more effective at reducing AFACS than

\section{Risk Factors for Perioperative AF}

- Age $>75$

- History of AF

- Renal Failure

- Mitral valve surgery/ disease

- Heart Failure

- COPD

There may be other important risk factors to consider in any individual patient

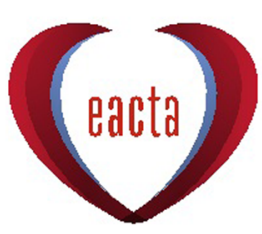

European Association of Cardiothoracic Anaesthesiologists

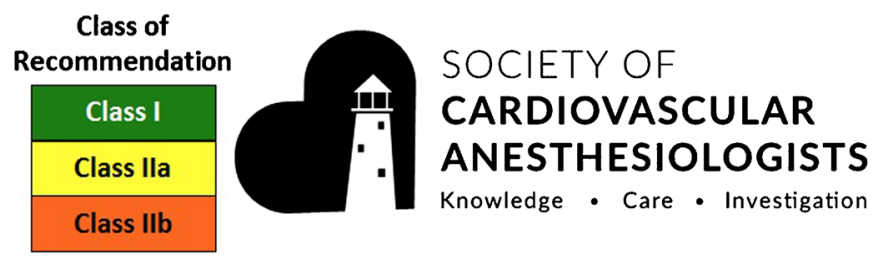

Practice Advisory for the Management of Perioperative Atrial Fibrillation in Patients Undergoing Cardiac Surgery. Anesth Analg. 2019;128(1):3342, accessible at https://journals.lww.com/anesthesia-analgesia/Fulltext/ 2019/01000/Society_of_Cardiovascular.11.aspx, with permission from Wolters Kluwer Health, Inc.

intravenous esmolol, and carvedilol may reduce AFACS more effectively than metoprolol, an effect that may be explained by carvedilol's oxidative stress-reducing properties [113]. In addition to continuing preoperative beta-blockers, the 2011 ACCF/AHA guideline for coronary artery bypass grafting (CABG) offers specific Class I recommendations to administer beta-blockers for at least 24 hours before CABG to all patients without contraindications to beta blockade, to reduce the incidence or clinical sequelae of AFACS [120]. Betablockers receive a Class I recommendation from multiple societies for AF prophylaxis (refer to Table 1).

Once AF has been initiated, multiple beta-blockers have been studied and found to be effective for rate control, although the most commonly used are esmolol and metoprolol [113]. All beta-blockers have some negative inotropic effects, with the ultrashort-acting beta-blocker landiolol potentially having the most limited impact on inotropy [113, 121]. 
Table 1 Strategies for prevention of AFACS

AFACS prophylaxis

\begin{tabular}{|c|c|c|c|}
\hline & Strategy & Level of evidence & Society recommendations \\
\hline \multirow{17}{*}{$\begin{array}{l}\text { Pharmacologic } \\
\text { prophylaxis } \\
\text { strategies }\end{array}$} & $\begin{array}{l}\text { Magnesium } \\
\text { supplementation }\end{array}$ & $\begin{array}{l}\text { Level I-intraoperative magnesium administration is } \\
\text { associated with decreased AFACS [49]. }\end{array}$ & None \\
\hline & $\begin{array}{l}\text { Potassium } \\
\text { supplementation }\end{array}$ & $\begin{array}{l}\text { Practice surveys - common practice to replete potassium } \\
\text { during the perioperative period for a target serum level of } \\
4.5-5.5 \mathrm{mEq} / \mathrm{L}[50,51] \text {. }\end{array}$ & None \\
\hline & $\begin{array}{l}\text { Beta-adrenergic } \\
\text { blockers }\end{array}$ & $\begin{array}{l}\text { Level I-perioperative use is associated with decreased } \\
\text { AFACS }[49,52-58] .\end{array}$ & $\begin{array}{l}\text { Class } I-[47,48,59-61] \text { specifically recommends the } \\
\text { administration of beta-blockers for at least } 24 \mathrm{~h} \text { in } \\
\text { patients with no contraindications. }\end{array}$ \\
\hline & Amiodarone & $\begin{array}{l}\text { Level I-perioperative use reduces incidence of AFACS; } \\
\text { useful in patients at high risk }[49,62-67] .\end{array}$ & $\begin{array}{l}\text { Class IIa- }[47,48,59,60] \text { Class IIa- }[61] \\
\text { recommends use as a second-line agent to prevent } \\
\text { AFACS when beta-blockade is contraindicated. }\end{array}$ \\
\hline & Sotalol & $\begin{array}{l}\text { Level I-perioperative use reduces incidence of AFACS; } \\
\text { however, there is a risk of significant bradycardia and } \\
\text { ventricular arrhythmias }[49,52,68-70] .\end{array}$ & $\begin{array}{l}\text { Class IIb-can be considered for patients at high risk } \\
\text { for AFACS. [47, 48, 59, 71] states that it has limited } \\
\text { utility due to adverse effects. }\end{array}$ \\
\hline & Ranolazine & $\begin{array}{l}\text { Level I-perioperative use reduces AFACS; however, larger } \\
\text { randomized trials are needed }[72,73] .\end{array}$ & None \\
\hline & $\begin{array}{l}\text { Non-dihydropyridine } \\
\text { calcium channel } \\
\text { blockers }\end{array}$ & $\begin{array}{l}\text { None-commonly used for treatment of AFACS but has not } \\
\text { shown promise as a prophylactic agent. }\end{array}$ & None \\
\hline & Digoxin & $\begin{array}{l}\text { None-commonly used for treatment of AFACS but has not } \\
\text { shown promise as a prophylactic agent. }\end{array}$ & None \\
\hline & Corticosteroids & $\begin{array}{l}\text { Level I-authors of a recent meta-analysis cautioned } \\
\text { that only small trials found an effect }[74-76]\end{array}$ & $\begin{array}{l}\text { Class IIb - the type and dose of an effective } \\
\text { corticosteroid remains to be established }[47,48] .\end{array}$ \\
\hline & NSAIDs & $\begin{array}{l}\text { Conflicting level } 1 \text { - use will also be limited by risks of renal } \\
\text { failure, bleeding, and myocardial ischemia }[77,78] \text {. }\end{array}$ & None \\
\hline & Colchicine & $\begin{array}{l}\text { Level I-reduction in recurrence of atrial fibrillation after } \\
\text { cardiac surgery or pulmonary vein isolation procedures } \\
\text { [79-83]. }\end{array}$ & Class IIb- $[47,48,59]$ \\
\hline & Statins & $\begin{array}{l}\text { Highly conflicting Level I-regarding association } \\
\text { with AFACS }[84,85] \text {. }\end{array}$ & None \\
\hline & PUFAs & Level I-significant reduction noted in AFACS [86-90]. & None \\
\hline & Levosimendan & $\begin{array}{l}\text { Conflicting level I-one meta-analysis found } \\
\text { decreased AFACS [91]; however, another did not[92]. }\end{array}$ & None \\
\hline & N-Acetylcysteine & $\begin{array}{l}\text { Level I-significant reduction in AFACS with IV or PO } \\
\text { administration }[89,93-95] \text {. }\end{array}$ & None \\
\hline & Vitamin C & $\begin{array}{l}\text { Level I-meta-analyses of small trials found a reduction in } \\
\text { AFACS }[89,96-99] \text {. }\end{array}$ & None \\
\hline & $\begin{array}{l}\text { Vasopressin vs } \\
\text { norepinephrine }\end{array}$ & $\begin{array}{l}\text { Level II- use of vasopressin intraoperatively or in the } \\
\text { immediate postoperative period is associated with } \\
\text { decreased AFACS compared to norepinephrine [100]. }\end{array}$ & None \\
\hline \multirow[t]{6}{*}{$\begin{array}{l}\text { Surgical } \\
\text { prophylaxis } \\
\text { strategies }\end{array}$} & Atrial pacing & $\begin{array}{l}\text { Level I- the prophylactic use of atrial pacing after cardiac } \\
\text { surgery is associated with significantly decreased AFACS } \\
\text { [49]. }\end{array}$ & Class IIb_ optimal pacing site(s) not specified $[47,48]$. \\
\hline & $\begin{array}{l}\text { Posterior } \\
\text { pericardiotomy }\end{array}$ & $\begin{array}{l}\text { Level I-significant reduction in AFACS in patients who } \\
\text { receive a posterior pericardiotomy compared with controls } \\
{[49,101,102] .}\end{array}$ & None \\
\hline & $\begin{array}{l}\text { Anterior fat pad } \\
\text { preservation }\end{array}$ & $\begin{array}{l}\text { Conflicting level II-whether preserving the anterior fat pad } \\
\text { decreases AFACS [103-105]. }\end{array}$ & None \\
\hline & $\begin{array}{l}\text { Botulinum toxin } \\
\text { (BTX) injection }\end{array}$ & $\begin{array}{l}\text { Conflicting level II-for whether injecting BTX } \\
\text { into the epicardial fat pads decreases AFACS [106-109]. }\end{array}$ & None \\
\hline & Off-pump CABG & $\begin{array}{l}\text { Level I-meta-analyses have found no effect } \\
\text { of on-pump vs off-pump CABG in } \\
\text { AFACS }[110,111]\end{array}$ & None \\
\hline & $\begin{array}{l}\text { Concomitant surgical } \\
\text { ablation }\end{array}$ & $\begin{array}{l}\text { None-may be used in patients with existing atrial fibrillation; } \\
\text { however, there is no evidence for whether it is useful as a } \\
\text { prophylactic strategy. }\end{array}$ & None \\
\hline
\end{tabular}

Beta-blockers have a Class I recommendation in multiple guidelines for use in rate control of AFACS (see Table 2).
Amiodarone Amiodarone has predominantly potassium channel-blocking antiarrhythmic properties, but also exhibits 
Table 2 Strategies for treatment of AFACS

AFACS treatment

\begin{tabular}{|c|c|c|c|}
\hline & Strategy & Level of evidence & Society recommendations \\
\hline \multirow[t]{4}{*}{ Rate control } & Beta-blockers & $\begin{array}{l}\text { Level II-most commonly used are esmolol and } \\
\text { metoprolol [122]. }\end{array}$ & $\begin{array}{l}\text { Class I-is recommended as a first-line agent for rate } \\
\text { control }[47,48,59] .\end{array}$ \\
\hline & $\begin{array}{l}\text { Non-dihydropyridine } \\
\text { calcium channel } \\
\text { blockers }\end{array}$ & $\begin{array}{l}\text { Level II-verapamil and diltiazem can be used in } \\
\text { patients who have contraindications to } \\
\text { beta-blockers, or in conjunction with beta-blockers } \\
{[122] \text {. }}\end{array}$ & $\begin{array}{l}\text { Class I-is recommended to use as a second-line } \\
\text { agent after beta-blockers }[47,48,59] \text {. }\end{array}$ \\
\hline & Digoxin & $\begin{array}{l}\text { None. Delayed rate control in digoxin compared to } \\
\text { diltiazem at } 2 \text { hrs after administration[122]. }\end{array}$ & Not specifically addressed. \\
\hline & Amiodarone & $\begin{array}{l}\text { Level II/III-also has rhythm control properties, and } \\
\text { is more effective at maintaining sinus rhythm when } \\
\text { compared with dronedarone, sotalol, flecainide, } \\
\text { and propafenone [122]. }\end{array}$ & Class IIa- $[47,48]$ \\
\hline \multirow[t]{4}{*}{ Rhythm control } & $\begin{array}{l}\text { Electrical } \\
\text { cardioversion }\end{array}$ & $\begin{array}{l}\text { Level III-R-wave synchronized direct-current } \\
\text { electrical cardioversion is indicated in } \\
\text { hemodynamically unstable patients, or with } \\
\text { evidence of myocardial ischemia, or infarction } \\
\text { [113]. }\end{array}$ & $\begin{array}{l}\text { Class IIa - it is reasonable to restore sinus rhythm } \\
\text { pharmacologically with ibutilide or direct-current } \\
\text { cardioversion in patients who develop AFACS, or } \\
\text { to administer antiarrhythmic medications in attempt } \\
\text { to maintain sinus rhythm in recurrent or refractory }\end{array}$ \\
\hline & $\begin{array}{l}\text { Ibutilide } \\
\text { sotalol }\end{array}$ & $\begin{array}{l}\text { None-have not been specifically studied in the } \\
\text { setting of cardiac surgery. }\end{array}$ & AFACS $[47,48,59,60]$. \\
\hline & & $\begin{array}{l}\text { Use with caution in QT prolongation, hypokalemia, } \\
\text { and reduced ejection fractions [60]. }\end{array}$ & \\
\hline & Vernakalant & $\begin{array}{l}\text { None - may be used for cardioversion of AFACS in } \\
\text { patients without severe heart failure, hypotension, } \\
\text { or severe structural heart disease, in particular aortic } \\
\text { stenosis [60]. }\end{array}$ & Class IIb- $[60]$ \\
\hline \multirow[t]{2}{*}{ Anticoagulation } & Anticoagulation & \multicolumn{2}{|c|}{ Antithrombotic therapy should be considered for AFACS lasting $\geq 48$ hrs or of unknown duration [60]. } \\
\hline & For cardioversion & \multicolumn{2}{|c|}{$\begin{array}{l}\text { Prior to cardioversion of } \mathrm{AF} \geq 48 \text { hrs or of unknown duration, TEE should be considered to rule out } \\
\text { intracardiac thrombus or cardioversion should take place only after } 3 \text { weeks of anticoagulation therapy has } \\
\text { been achieved, after which, anticoagulation should be maintained for } 4 \text { weeks after; there is no further } \\
\text { indication for continued antithrombotic therapy[60]. }\end{array}$} \\
\hline
\end{tabular}

Society guidelines

[47, 48] 2019 SCA/EACTA Practice Advisory for the Management of Perioperative Atrial Fibrillation in Patients Undergoing Cardiac Surgery

[71] 2017 EHRA/EACPR/HRS/APHRS Position Paper on How to Prevent Atrial Fibrillation

[60] 2016 ESC/EACTS Guidelines for the Management of Atrial Fibrillation

[59] 2011 ACCF/AHA/HRS Focused Updates of the Guidelines for the Management of Patients with Atrial Fibrillation

[61] 2011 ACCF/AHA Guideline for Coronary Artery Bypass Graft Surgery

some degree of action at the beta-adrenergic receptor, sodium and calcium channels [113]. Amiodarone use is associated with adverse events such as bradycardia and hypotension, as well as potential pulmonary, hepatic, and thyroid toxicity, though rarely with short-term use [49, 114]. Its long-term use requires regular monitoring of liver and thyroid function [123]. Amiodarone is also contraindicated in patients with an accessory pathway and can cause bradycardia and QT-interval prolongation [113]. A 2013 meta-analysis of 33 RCTs $(n=$ 5402) found a significant reduction in AFACS in patients who received prophylactic amiodarone compared to that in controls (19.4\% vs 33.3, OR 0.43, CI 0.34-0.54, $I^{2}=63 \%$ )[49]. However, dosage regimens and administration routes, including loading doses and infusion rates, varied between studies [49]. There was a reduction in length of stay for those patients receiving prophylactic amiodarone compared with controls, but no decrease in mortality [49••]. Amiodarone receives a Class IIa recommendation by the ACC/AHA/HRS, ACCF/AHA, ESC guidelines and the SCA/EACTA Practice Advisory for AF prophylaxis.

Amiodarone has also been studied as a treatment for AFACS once it occurs. It is an effective rhythm control agent that also has rate-control properties. Authors of a 2011 database study of dronedarone, amiodarone, sotalol, flecainide, and propafenone in AF patients reported that even though amiodarone was most effective at maintaining sinus rhythm, they found a trend toward higher mortality in patients on amiodarone when compared with the other pharmacological agents [124]. Some authors caution that ruling out intracardiac thrombi by transesophageal echocardiogram (TEE) should be considered before using amiodarone to treat AFACS of 24 48-hrs duration, as discussed further below under 
"Anticoagulation" [113]. As noted in Table 2, amiodarone has a Class IIa recommendation from the SCA/EACTA Practice Advisory for use in the treatment of AFACS.

Sotalol Sotalol is an antiarrhythmic drug with both betaadrenoreceptor and potassium channel-blocking activity [68]. Its utility is limited due to the risk of significant bradycardia, QT prolongation, and ventricular arrhythmias including torsades de pointes, particularly in patients with electrolyte disturbances [116, 119]. A 2013 meta-analysis of 11 studies $(n=1609)$ concluded that sotalol was associated with a significant reduction in AFACS compared with that of controls (18.1\% vs $40.0 \%$, OR $0.34,95 \%$ CI $0.26-0.43, I^{2}=3 \%$ ) [49••]. However, many of the trials in this meta-analysis used beta-blockers instead of placebos in the control groups [114]. Another meta-analysis which specifically compared patients receiving sotalol to those receiving beta-blockers reported that the sotalol group had a decrease in AFACS compared to the beta-blocker group (OR 0.42, 95\% CI 0.26-0.65) [52, 114]. Sotalol receives Class IIb recommendations by multiple societies for AF prophylaxis in high-risk patients (refer to Table 1).

Sotalol has been well-established for the pharmacological conversion and maintenance of sinus rhythm in the general population with AF [125], but has been less well-studied specifically in the setting of AFACS treatment. Since many AFACS treatment options have been adapted from treatment of AF in general, it would be reasonable to extrapolate its use to the cardiac surgical population as well. Its use in the postoperative setting might be limited by any hypotension and renal impairment, particularly in patients with heart failure, and like many other antiarrhythmic agents, should include close monitoring of serum electrolyte levels and the QT interval (3).

Ranolazine Ranolazine received FDA-approval as an antianginal medication in 2006 and has an acceptable safety profile even in patients with structural heart disease [126]. It has antiarrhythmic effects resembling that of amiodarone, inhibiting inward sodium and rectifying potassium channels, resulting in prolonged effective refractory period in the atria [126]. Ranolazine has been found to be an effective rhythm control strategy with few adverse events in the general population with AF [126]. In cardiac surgical patients, two recent meta-analysis of the same 4 studies (all single center, 2 retrospective, 1 prospective, 1 randomized trial) have been published, and both report that starting ranolazine preoperatively was associated with a significant reduction in AFACS events, with one meta-analysis reporting $13 \%$ AFACS in the ranolazine group compared with $32 \%$ in controls [72], and the other a risk ratio of $0.44((0.25,0.78), p=0.005)$ [73]. The authors note that although the pooled treatment effect of a greater than $50 \%$ risk reduction appears impressive, they cannot make definite conclusions due to the small number of studies and heterogeneity in ranolazine dose regimens [73]. Ranolazine's potential role in AF prophylaxis has not yet been addressed by specific guidelines, but it appears to hold some promise.

Non-dihydropyridine Calcium Channel Blockers Calcium channel blockers are a potential alternative in patients where beta-blockers are contraindicated [114]. However, most of the evidence for their use pertains to heart rate control in patients with AF and there is little evidence to support their prophylactic use to prevent AFACS. They are contraindicated in patients with left ventricular impairment, which may limit their use in this patient cohort. While a 2003 meta-analysis of RCTs found that the preoperative, intraoperative, or early postoperative (within $48 \mathrm{hrs}$ ) use of non-dihydropyridine calcium channel blockers was associated with a significant decrease in supraventricular arrhythmias, adverse effects in the form of increased atrioventricular blocks and low cardiac output syndrome limit their use [114]. This class of agents is not referenced for prophylaxis in any society guidelines to date.

In the AFACS treatment setting, verapamil and diltiazem are more often used in patients who have contraindications to beta-blockers, or in conjunction with beta-blockers [113]. RCTs comparing beta-blockers to non-dihydropyridine calcium channel blockers have found that the calcium channel blockers are less effective for rate control when used as the sole agent and are associated with more hypotension [121, 127], which is more pronounced with verapamil [113]. Of note, these are also contraindication in patients with an accessory pathway [113]. Calcium channel blockers receive a Class I recommendation from multiple societies for their use in AFACS rate control (See Table 2).

\section{Anti-inflammatory Agents}

Corticosteroids A 2011 meta-analysis of 14 RCTs $(n=1974)$ found that steroid prophylaxis was effective against AFACS (25.1\% vs $37.3 \%$ in controls, OR $0.56,95 \%$ CI $0.44-0.72$, $p<0.0001)$. There was significant heterogeneity amongst the studies regarding the type of steroid received: methylprednisolone $(51.4 \%)$, dexamethasone $(34.3 \%)$, hydrocortisone $(5.7 \%)$, prednisolone $(2.9 \%)$, or a combination of methylprednisolone and dexamethasone (5.7\%) [74]. The authors also observed that steroid administration was not associated with an increased risk of postoperative infection, need for re-exploration, or mortality [74].

A 2009 meta-analysis of RCTs $(n=1046)$ aimed at determining the impact of different corticosteroid regimens concluded that overall corticosteroid use is associated with a reduced risk of AFACS and this effect became more prominent when low-dose and very high-dose steroid studies were excluded (OR 0.32, 95\% CI 0.21-0.50, $p<0.00001$ ) [75]. They 
concluded that a single dose of moderate-dose hydrocortisone should be considered at induction for the prevention of AFACS in high-risk patients. The authors of a 2018 metaanalysis of 56 RCTs $(n=16,013)$ echoed the overall findings that new-onset AFACS was lower in the steroid group (25.7\% vs $28.3 \%$, RR $0.91,95 \%$ CI $0.86-0.96, p=0.005, I^{2}=43 \%$ ), but cautioned that this effect was driven by only small trials, and larger trials showed no effect [76].

The optimal dose of steroids, interval and total therapy duration has yet to be established. Perioperative use may also have potential adverse effects on glucose metabolism, wound healing, and infection [119]. As a result, the use of corticosteroids is summarized as a Class IIb recommendation by the SCA/EACTA 2019 Practice Improvement Advisory for AF prophylaxis. So far, corticosteroids are not widely used for the purpose of prevention of AFACS.

Non-steroidal Anti-inflammatory Drugs Transient interest in the use of non-steroidal anti-inflammatory drugs (NSAIDs) started with a single-center 2004 RCT that randomized 100 patients undergoing CABG to an NSAID regimen (of intravenous ketorolac in the immediate perioperative period followed by oral ibuprofen) vs placebo [77]. These authors found the NSAID group had significantly reduced AFACS $(9.8 \%$ vs $28.6 \%, p=0.017$ ) without any difference in renal failure [77]. A subsequent RCT of CABG patients comparing naproxen vs placebo discontinued enrollment early, due to a significantly higher rate of renal failure in the naproxen group. These authors found no significant reduction in AFACS in the naproxen group amongst the 161 (out of an intended 200) enrolled patients $(15.2 \%$ vs $7.3 \%, p=0.11)$ [78] but may have been underpowered to detect a statistically significant difference. In addition to the risk of renal failure, the use of NSAIDs in cardiac surgery is limited by a potential risk of bleeding, and particularly with the COX-2 inhibitors, myocardial ischemia, or infarction [116]. With the lack of RCTs and the adverse effect profile, NSAIDs are not used routinely for preventing AFACS and have not been addressed by guidelines.

Colchicine Colchicine also has potent anti-inflammatory properties [113], and its role in AFACS prevention was addressed by multiple meta-analyses [79-82]. The most recent metaanalysis included 5 RCTs $(n=1412)$, and the authors reported that patients receiving colchicine had a significant reduction in AFACS when compared with those receiving placebo (18\% vs $27 \%$, risk ratio $0.69,95 \%$ CI $0.57-0.84, p=0.0002$ ) and a 1.2 day decrease in hospital length of stay but no significant change in major adverse events [83]. Gastrointestinal intolerance was the main adverse effect. With its relatively good adverse effect profile and growing, but not conclusive, evidence to support efficacy as primary prevention, the SCA/ EACTA Practice Advisory summarizes a Class IIb recommendation for colchicine in AFACS prevention although it is not used widely for this purpose.

\section{Antioxidant agents}

Statins The theorized mechanism of action of statins is multifactorial [113], and there are numerous studies using statins as an intervention in cardiac surgical patients. Two metaanalyses were published in 2016: One specifically included RCTs of statin-naïve patients who were randomized to statin vs placebo and found that statin therapy was associated with a significant reduction in AFACS (RR 0.50, 95\% CI 0.41-0.61, $p<0.0001$ ) [128]. The other found only two trials with low risk of bias that reported atrial fibrillation as an outcome and concluded that there was no difference in the rate of AFACS in statin vs placebo groups $(25.07 \%$ vs $23.6 \%$, OR $1.08,95 \% \mathrm{CI}$ $0.9-1.3, p=0.40$ ) [84]. Conversely, a 2014 meta-analysis found that patients on statins had a $32 \%$ reduced risk of new-onset AFACS compared with controls, after adjusting for publication bias (OR 0.68; 95\% CI 0.54-0.85) [85]. This series of conflicting studies is representative of preceding reviews and meta-analyses. The routine use of statins in AFACS prophylaxis remains controversial, but a high proportion of adult patients undergoing cardiac surgery will already have an indication for statin use, and it is rare that there is a reason to stop these agents perioperatively.

Polyunsaturated Fatty Acids Polyunsaturated fatty acids (PUFAs) are a dietary antioxidant with possible benefits to overall cardiovascular morbidity shown in animal models. There is limited evidence for their use in AFACS prophylaxis [119]. Early trials have not shown a reduction in AFACS [113], and a 2014 meta-analysis of 8 RCTs $(n=2687)$ concluded that preoperative PUFA treatment did not influence AFACS incidence [86]. In 2017, a meta-analysis of 19 RCTs $(n=4335)$ found a reduction in AFACS [87], and so did a 2018 meta-analysis that included 14 RCTs $(n=3570)$, which found significant AFACS reduction with PUFA vs controls (OR $0.84,95 \%$ CI $0.71-0.99, p=0.03$ ), although this effect was found only in CABG and not valve surgery [88]. This appears to be a promising intervention for AF prophylaxis, which may incur few risks from adverse effects and costs, but has not been addressed by any guidelines to date.

Levosimendan While levosimendan was not introduced for its current indications in heart disease as an antioxidant, some authors have proposed that its antioxidant properties could help in AFACS prophylaxis [113]. Levosimendan works to augment myocardial inotropy by increasing myofilament sensitivity to calcium without increasing myocardial oxygen consumption $[113,129]$. There is conflicting evidence about whether the use of levosimendan protects against or predisposes to AFACS: 1 RCT of 200 patients whose primary 
endpoint was AFACS found a decrease in the levosimendan group compared to controls $(12 \%$ vs $36 \%, p<0.05)[130]$. All other studies have evaluated AFACS as a secondary outcome, and meta-analyses have found either no difference [92] or an increase [131] in AFACS in patients receiving levosimendan. It is unlikely that levosimendan will be ever used solely for the purpose of AFACS prophylaxis.

N-Acetylcysteine N-Acetylcysteine (NAC) has free radical scavenging and antioxidant properties and has showed promising results in two meta-analyses [93, 94]. A meta-analysis carried out in 2014 included 10 RCTs $(n=1026), 8$ of which administered NAC intravenously, and 2 orally, and found a reduction in AFACS incidence when compared to controls (OR 0.56 ; 95\% CI 0.4-0.77, $p<0.001$ ) and all-cause mortality (OR $0.40,95 \%$ CI $0.17-0.93, p=0.03$ ) without a difference in the cerebrovascular events, ICU or hospital stay [94]. In 2016, a further meta-analysis found the same 10 RCTs $(n=$ 1026) that reported AFACS as an outcome and it reported the same finding [89]. A recent RCT of 150 patients undergoing on-pump CABG randomized to $50 \mathrm{mg} / \mathrm{kg}$ IV NAC or placebo found a significant decrease in AFACS $(5.6 \%$ vs $18.8 \%$, OR $0.23,95 \%$ CI $0.08-0.82, p=0.02$ ) [132]. N-Acetylcysteine appears promising and has a few adverse effects, but has not been addressed specifically by any guidelines for routine use.

Vitamin C Vitamin C is another agent that may reduce oxidative stress and has been studied in a few small trials for AFACS prophylaxis. A 2016 meta-analysis of 7 RCTs $(n=$ 785) found a reduction in AFACS in patients randomized to vitamin $\mathrm{C}$ vs placebo (OR: $0.40,95 \%$ CI $0.23-0.68, p=$ 0.001) [89]. More recently, an RCT of 314 on-pump CABG patients found no difference in AFACS, ICU or hospital lengths of stays [133]. No guidelines currently reference its use for AF prophylaxis.

Combined Antioxidants A 2013 study randomized 203 cardiac surgical patients to a combined regimen of Vitamins $\mathrm{C}$, and $\mathrm{E}$ and PUFAs. The authors found a significantly reduced incidence of AF in the patients receiving antioxidants compared to controls $(9.7 \%$ vs $32 \%$, RR 0.28 , 95\% CI $0.14-0.56$, $p<0.001)$. The authors suggest that the simultaneous use of these antioxidants has potential for being effective, safe, and low-cost AFACS prophylaxis [134]. However, no guidelines currently reference such a protocol.

\section{Vasopressor Agents}

The recent Vasopressin vs Norepinephrine in Patients with Vasoplegic Shock after Cardiac Surgery (VANCS) trial found that using vasopressin to treat vasoplegia after cardiac surgery - compared to norepinephrine - was associated with a lower occurrence of atrial fibrillation $(63.8 \%$ vs $82.1 \%$; $p=$
$0.0004)$ [100]. The composite end point of 30-day mortality or severe complications was also decreased in the vasopressin group (32\% vs $49 \%$ unadjusted hazard ratio, $0.55 ; 95 \% \mathrm{CI}$, $0.38-0.80 ; p=0.0014)[100]$. The authors suggest this may be the result of reduced beta- 1 receptor stimulation in the atrial myocardium by a non-catecholaminergic agent. Although these data might inform a choice between vasopressor agents, it is unlikely that vasopressin will ever be used solely for the purpose of AFACS prophylaxis.

\section{Electrophysiological or Surgical Strategies}

Atrial Pacing The use of prophylactic overdrive atrial pacing after cardiac surgery improves intra-atrial conduction and prevents triggering events such as premature atrial contractions or atrial refractoriness $[13,114]$. Multiple studies report favorable results with the use of right atrial pacing, left atrial pacing, Bachmann's bundle pacing, and bi-atrial pacing [49, 52, 113, 135, 136]. A 2013 Cochrane database review and metaanalysis including 21 RCTs $(n=2933)$ found a significantly decreased AFACS incidence in all pacing groups $(18.7 \%$ in pacing groups and $32.8 \%$ in control groups, OR 0.47 , CI $0.36-0.61, I^{2}=50 \%$ ) [49]. It is less clear whether the site of pacing has a further impact on efficacy. An earlier 2006 metaanalysis of 14 RCTs reported that a significant reduction in AFACS occurred with bi-atrial pacing but not with single-site right or left atrial pacing alone [52]. Other authors have suggested that epicardial pacing could have pro-arrhythmic properties [137] and that right atrial pacing is the most effective site for preventing AFACS $[114,138]$. Routine use of prophylactic pacing is limited by the potential risks associated with placement or removal of temporary pacing wires, such as mediastinal infection and damage to coronary grafts or atriotomy sites resulting in tamponade [116]. The use of atrial pacing has been summarized by the SCA/EACTA Practice Advisory as Class IIb for the prophylaxis of AF.

Posterior Pericardiotomy A posterior pericardiotomy allows pericardial fluid to drain out of the pericardial space, thus decreasing the accumulation of pericardial effusions, which may be a trigger for atrial fibrillation and supraventricular tachyarrthythmias [101]. Three meta-analyses have been published: a 2010 meta-analysis of 6 RCTs $(n=763)$ found that there was a significant decrease in AFACS in the posterior pericardiotomy group when compared with that in the control group $(10.8 \%$ vs $28.1 \%, p=0.003$, OR $0.33,95 \%$ CI $0.16-$ 0.69) [101]. A 2013 meta-analysis found the same 6 published RCTs, and similarly reported a significant reduction in AFACS [49]. In 2016, a meta-analysis identified 10 RCTs $(n=1648)$ and also found that patients receiving a posterior pericardiotomy had a decreased incidence of AFACS $(10.6 \%$ compared with $24.9 \%$ in controls, $I^{2}=55 \%, p<0.00001$, OR $0.36,95 \%$ CI $0.23-0.56$ ) [102]. There appears to be consistent 
evidence from this small number of studies for using a posterior pericardiotomy as a prevention strategy for AFACS, although this has not been conclusively proven in an adequately powered study and has not been addressed by any society guidelines to date. While this is a relatively simple intervention with favorable data, potential risks that authors have pointed out include the potential for compression of bypass grafts or cardiac herniation $[101,102]$.

Epicardial Fat Pad Manipulations The autonomic nervous system may contribute to AFACS susceptibility, as atrial tissue receives extensive cholinergic innervation, and an enhanced vagal tone results in decreased atrial refractoriness [103, 139]. Vagal postganglionic neurons are located in distinct anatomic fat pads distributed around the heart, including the anterior epicardial fat pad, and interventions targeting these neurons were hypothesized to have an effect on AFACS. To date, these interventions are not referenced for AFACS prophylaxis in any guidelines.

\section{Anterior Fat Pad Preservation vs Dissection or Removal} Dissecting the epicardial fat pad to reveal an aortopulmonary window for aortic cannulation and cross-clamp placement is a routine step in cardiac surgery. Some authors have hypothesized that the disruption [103] or removal [104] of the anterior fat pad might be useful in decreasing AFACS. However, in a study of 55 patients undergoing $\mathrm{CABG}$, the incidence of AFACS was significantly lower in the group randomized to anterior fat pad preservation than the group with anterior fat pad dissection (7\% vs $37 \%, p<0.01)$ [103]. Contradictory results from a study of 180 patients concluded that preserving the anterior fat pad did not reduce AFACS [105]. A 2015 meta-analysis that included 7 RCTs $(n=991)$ concluded that the removal of the anterior fat pad did not lead to a decreased risk of AFACS, but did not examine the question of whether the converse was true - that is, whether preserving the fat pad would influence AFACS risk [104]. Further studies are required before a recommendation can be made about how surgical manipulation of the anterior fat pad might affect AFACS.

Fat Pad Botulinum Toxin Injection The protein botulinum toxin (BTX) prevents the release of the neurotransmitter acetylcholine from axon endings at the neuromuscular junction, and this suppression of vagal tone has been found to reduce AF in multiple animal models. A prospective, randomized, doubleblind study of 60 patients in 2014 found promising results: CABG patients with a history of paroxysmal but not persistent or permanent forms of AF who received BTX injections into four major epicardial fat pads prior to aortic cross-clamp release had a lower incidence of AFACS than those receiving normal saline ( $7 \%$ vs $30 \%, p=0.024)$ [106]. Amongst the patients who had AFACS, the AF burden was also lower in the BTX group $(0.3 \%$ vs $2.5 \%, p=0.08)$ [106], and at 1 -year follow-up recurrent atrial fibrillation was also significantly lower in the BTX group (27\% vs $0 \%, p=0.002)$. In their 3 year follow-up, the BTX group still had decreased incidence of $\mathrm{AF}(23.3 \%$ vs $50 \%$ in placebo group, hazard ratio 0.36 , 95\% CI 0.14-0.88, $p=0.02$ ) [107]. However, another RCT of 130 patients where only 4 patients had a history of AF found a trend that failed to reach statistical significance (36.5\% vs $47.8 \%$ in placebo, $p=0.18$, absolute risk reduction of $11 \%$ ) [109]. This suggests that the effect size of BTX fat pad injections might be smaller in AF-naïve patients and it may be a more useful intervention for decreasing AFACS incidence in patients who already have a history of paroxysmal AF.

Concomitant Surgical Ablation Preoperative AF has been identified as a risk factor for AFACS [140], and AF ablation surgery has been shown to improve outcomes in patients with paroxysmal AF undergoing cardiac surgery [141-144], although one of these studies also reported that at 1-year follow-up, there was no difference in the quality of life [145]. There are no available data about whether AFACS is reduced by the prophylactic intraoperative ablation in patients without a history of AF $[113,146]$, and this issue has not been addressed in the guidelines.

Off-pump Coronary Artery Bypass Grafting The inflammatory response to cardiopulmonary bypass (CPB) has been identified as a potential contributor to AFACS. Therefore off-pump $\mathrm{CABG}$, which has been found to have a decreased inflammatory response, could in theory decrease AFACS [113, 147]. However, there is little evidence that off-pump CABG decreases AFACS incidence when compared to on-pump CABG. An analysis of the "Randomized On Versus Off Bypass" trial, which included 2103 patients, found no increase in the rate of AFACS in on-pump vs off-pump CABG [148]. A 2012 meta-analysis of 34 trials $(n=3392)$ showed that although there may be a significant intervention effect in favor of off-pump CABG (RR 0.86; 95\% CI 0.76-0.96, $p=0.008$ ), no significant difference was found when only trials with low risk of bias were included [110]. More recently, the randomized controlled multicenter German Off-Pump CABG in the Elderly trial of 2303 patients also found the same rate of AFACS in both groups [111]. In the ongoing debate about the merits of on-pump vs off-pump CABG, the influence of either strategy on the incidence of AFACS is unlikely to tip the scales.

\section{Treatment Strategies and Associated Evidence Base}

The treatment strategies for AFACS depend on hemodynamic stability and clinical symptoms. The approach to a hemodynamically stable patient is broadly classified into rate control, 
rhythm control, and concomitant thromboprophylaxis [113]. These treatment strategies and the associated strength of society recommendation, if available, are summarized in Table 2.

\section{Rate vs Rhythm Control}

Available data suggest that most cases of AFACS return to a sinus rhythm at the end of $24 \mathrm{hrs}$ regardless of treatment strategy [113, 123, 149]. An RCT published in 2000 randomized 50 cardiac surgery patients with new-onset AF to rate vs rhythm control and found no difference in the time of conversion to sinus rhythm $(11.8 \pm 3.9 \mathrm{hrs}$ vs $11.2 \pm 3.2, p=0.8)$ and no difference in relapse rates for the 2-month follow-up duration, although hospital length of stay was reduced in the antiarrhythmic arm [149].

Rate control is generally the recommended strategy by available guidelines that address AFACS [113, 149, 150] for hemodynamically stable patients within the first $24 \mathrm{hrs}$ of AF. A multicenter trial randomized 523 cardiac surgical patients to rate control (ventricular rate less than $100 \mathrm{bpm}$ ) vs rhythm control (amiodarone followed by electrical cardioversion if AF persisted for 24-48 hrs) [151]. There was no detectable difference in the proportion of patients who were free from atrial fibrillation in the rate vs rhythm control groups at 30 days $(84.2 \%$ vs $86.9 \%, p=0.41)$ or 60 days $(93.8 \%$ vs $97.9 \%, p=$ $0.02)$ after discharge [151]. There was also no difference between the groups in hospital length of stay, rates of death, and overall adverse events including thromboembolic and bleeding events [151]. However, there was a $25 \%$ crossover between groups. The authors note that rate control strategies avoided many side effects of rhythm control drugs and did not make a significant difference in postoperative outcomes [151]. This large study has led some authors to suggest that in cardiac surgical patients, new-onset AF is a self-limiting disease which often resolves regardless of its initial treatment [152]. The overall impact of increased AF burden (frequency and duration of AF) in AFACS has not been conclusively understood.

The most frequently used agents for rate control are betablockers and non-dihydropyridine calcium channel blockers, and these can potentially be used in combination [113]. A variety of target ventricular rates, from $80-110 \mathrm{bpm}$, have been proposed [106]. The cumulative effects of drugs given for controlling the ventricular response rate in AF can cause problematic bradycardia in the event of spontaneous cardioversion to sinus rhythm.

SCA/EACTA, ESC, and ACC/AHA/HRS guidelines all include Class IIa recommendations for managing asymptomatic patients with rate control and anticoagulation, with $\mathrm{ACC} /$ AHA/HRS guidelines also recommending cardioversion if the AF does not spontaneously revert to sinus rhythm during subsequent follow-up [123].

\section{Digoxin}

While digoxin does not decrease the incidence of AFACS [113], and thus it is not recommended for prophylaxis, the EHRA/EACPR/HRS/APHRS [119] and ACC/AHA/HRS $[59,123]$ guidelines describe its treatment role for rate control in the management of patients with rapid ventricular responses. Digoxin has a slower onset of action and may be less effective in the setting of high catecholaminergic states, for instance in postoperative patients [113]. One RCT assessing AFACS reported significantly fewer patients achieved rate control with digoxin when compared to diltiazem at 2 hrs ( $75 \%$ vs $35 \%$, $p=0.03)$ and $6 \mathrm{hrs}(85 \%$ vs $45 \%, p=0.02)$ following drug administration; however, the 12- and 24-hr response rates were similar [153]. When used together with other rate control agents, digoxin may have a dose-sparing effect for concomitant beta-blocker or calcium channel blocker, and this potentially avoids some degree of hypotension [113]. However, digoxin is also contraindicated in patients with significant renal impairment or an accessory pathway [113].

Rhythm Control Interventions Paroxysmal AF is associated with electrical and structural remodeling of the heart, which has been identified as a cause of progression to persistent $\mathrm{AF}$ $[113,119]$. ESC and ACC/AHA/HRS practice guidelines state that it is reasonable to restore sinus rhythm pharmacologically with ibutilide or direct-current cardioversion in patients who develop AFACS, or to administer antiarrhythmic medications in an attempt to maintain sinus rhythm in recurrent or refractory AFACS $[59,123,150]$. In patients at a risk of postoperative bleeding, it has been suggested that rhythm control may also help to avoid the need for anticoagulation therapy that is conventionally indicated for AFACS lasting longer than $48 \mathrm{hrs}$ [113].

\section{Electrical Cardioversion}

R-wave synchronized direct-current electrical cardioversion (DCCV) is indicated for AFACS patients with hemodynamic instability, or with evidence of acute myocardial ischemia or infarction [5, 106, 113]. If restoration of sinus rhythm is attempted more than $48 \mathrm{hrs}$ after the onset of AFACS, exclusion of intracardiac thrombus (most commonly seen in the left atrial appendage) and/or anticoagulation should be considered prior to electrical or chemical cardioversion [113], as discussed in further detail below. If there is a need for repeat cardioversion, concurrent pharmacologic rhythm or ratecontrol drugs can be considered to optimize successful and sustained cardioversion [113]. To our knowledge, no comparison of the effectiveness of electrical vs chemical cardioversion has been undertaken. It has been reported that only 1 in 10 patients with AFACS receive electrical cardioversion compared with three quarters who receive amiodarone [11]. 


\section{Pharmacologic Cardioversion}

The mechanism of action of antiarrhythmic agents involves some degree of interference with myocyte sodium and/or potassium channels. Other than amiodarone and beta-blockers (discussed previously), the available antiarrhythmic agents include vernakalant, ibutilide, flecainide, propafenone, dronedarone, disopyramide, and quinidine [113]. None of them have been studied specifically in the setting of cardiac surgical patients, and practice guidelines are based on evidence from other AF populations.

Ibutilide In the ACC/AHA/HRS practice guidelines, ibutilide is specifically named as a reasonable choice of pharmacological agent for restoring sinus rhythm in AF [123]. It is associated with ventricular arrhythmias including sustained polymorphic ventricular tachycardia, requires close rhythm monitoring for at least $4 \mathrm{hrs}$ after administration, and it is contraindicated in patients with QT prolongation, hypokalemia, and reduced ejection fractions $[113,154]$.

Vernakalant Vernakalant was approved in 2010 by the European Medicines Agency for the cardioversion of newonset $\mathrm{AF}$ of 3 days or less in cardiac surgical patients and also for the cardioversion of other AF less than 7 days in duration. There have been 4 RCTs evaluating the efficacy of vernakalant in new-onset $\mathrm{AF}$, three of which compared the drug against placebo [155-157] and one superiority study with amiodarone in the control group [158]. Only one of these specifically recruited cardiac surgical patients with new AF, and these authors found that vernakalant converted $47 \%$ of patients to sinus rhythm within 90 min, compared with $14 \%$ of patients receiving placebo $(p<0.001)$ [155]. All reported that vernakalant was safe and when compared with placebo, resulted in rapid conversion to sinus rhythm within $90 \mathrm{~min}$ [155-158]. The ESC guidelines contain a Class IIb recommendation to consider vernakalant for cardioversion of POAF in patients without severe heart failure, hypotension, or severe structural heart disease, in particular aortic stenosis [150]. It also prolongs the QT interval; however, none of the 4 RCTs reported torsades de pointes, polymorphic, or other sustained ventricular tachycardia [155-158]. A recent observational study that characterized its use in post-cardiac surgical patients found that $44 \%$ of patients who received vernakalant converted to sinus rhythm after one $3-\mathrm{mg} / \mathrm{kg}$ dose, and another $32 \%$ converted after a second dose of $2 \mathrm{mg} / \mathrm{kg}$, with a mean time to conversion of $13.7 \pm 14.1 \mathrm{~min}$ [159]. These authors also reported that patients receiving vernakalant had a decreased conversion rate if they had no preoperative beta-blocker, postoperative troponin levels $>500 \mathrm{ng} / \mathrm{ml}$, and systolic blood pressures $>140 \mathrm{mmHg}$ and if they had undergone valve surgery (as opposed to isolated CABG) [159]. At their first follow-up clinic visit after discharge, $92 \%$ of responders were in sinus rhythm, compared with $80 \%$ of non-responders $(p<0.01)$ [159]. Vernakalant has not been approved in the USA but is recommended by European societies (refer to Table 2) for the pharmacologic conversion of POAF.

\section{Electrophysiological or Surgical Interventions}

In patients with persistent forms of $\mathrm{AF}$, interventions such as catheter ablation, or atrioventricular nodal ablation with permanent pacemaker implantation, may help to restore regular ventricular rhythm [113]. However, as discussed above, many AFACS patients return to a sinus rhythm in time and these interventions are not typically utilized in the immediate postoperative setting [106, 151].

\section{Anticoagulation}

Current recommendations from multiple societies (refer to Table 2) indicate that it is reasonable to consider antithrombotic therapy for AFACS lasting more than $48 \mathrm{hrs}$ or of an unknown duration, as advised for nonsurgical patients $[123,150]$. $\mathrm{AF}$ is a risk factor for thromboembolic events including thromboembolic stroke, and stroke risk can be assessed by scoring systems such as the CHADS2 [160] or CHADS2VASC [35] score. Any antithrombotic therapy also increases bleeding risk, which must be carefully considered particularly, in the immediate postoperative period, and scoring systems for this have been developed in the form of the HAS-BLED [161], ATRIA [162], and HEMORR2HAGES [163] scores, albeit not specifically in the setting of cardiac surgery. It remains uncertain whether AFACS conveys the same thromboembolic risk as AF occurring outside of this context. It has also been reported that the CHA2DS2VASC score can predict postoperative stroke risk, independent of the presence of AF [164]; delayed postoperative strokes are traditionally attributed to postoperative AF but these data do not support this concept.

The long-term prognosis of AFACS that reverts early to sinus rhythm is also uncertain. Studies of AF in patients admitted to intensive care units for sepsis have shown an increased lifetime risk with increasing AF burden during the critical care episode [165].

\section{Anticoagulation and Cardioversion}

Cardioversion also poses a risk of stroke in non-anticoagulated patients [150]. Prior to cardioversion in patients with AF lasting more than 48 hrs or of unknown duration, antithrombotic therapy or transesophageal echocardiography (TEE) should be carried out to exclude the presence of any intracardiac thrombus, particularly in the left atrial appendage $[166,167]$. TEE imaging might be useful to facilitate safe cardioversion for postoperative patients in whom bleeding risk is high. ESC guidelines state that in 
patients with an identified thrombus, cardioversion should not be performed until at least 3 weeks of anticoagulation therapy has been achieved, and anticoagulation should be continued for 4 weeks after if there is no other indication for long-term anticoagulation [150].

\section{Areas for Further Investigation}

As described above, there is a paucity of definitive data in the form of appropriately powered randomized controlled trials to determine whether a successful reduction in AFACS burden by means of the above prevention and treatment strategies translates into a meaningful decrease in adverse outcomes, such as cerebrovascular events or other thromboembolic events, morbidity from anticoagulation, mortality, critical care or hospital lengths-of-stays, or quality of life. Unfortunately, as eloquently noted by Sessler in his recent call to action [168], this lack of adequately sized trials providing clinically actionable results is not limited to AFACS investigations but is widespread across many disciplines.

It remains uncertain whether prophylactic interventions to prevent AFACS should be limited only to high-risk patients or whether all patients should receive at least some of these interventions.

The only recent meta-analysis analyzing multiple interventions for the prevention of AFACS found that no individual intervention was associated with a significant effect on postoperative mortality, and the authors acknowledged that they were significantly limited by the lack of relevant secondary outcome data [49]. One possibility for the dearth of effective AFACS interventions is the fact that many attempted strategies have been developed from extrapolated data from patients with primary AF. While the initiation of AF in the primary, non-surgical setting and the secondary, postoperative setting is both multifactorial in etiology and likely to have some amount of mechanistic overlap, there may be causes of a susceptible substrate and triggering factors that are more specific to the primary or secondary context. For example, during the immediate postoperative period, factors such as myocardial ischemia/reperfusion injuries, the presence of direct surgical injury, rapid fluid shifts with electrolyte changes, and use of exogenous inotropic agents create a markedly different physiologic environment than that seen surrounding primary AF. Further, there is signal in the data that suggests there is more than one phase of AF risk in the postoperative period [26] consistent with the idea that multiple sets of predisposing/triggering mechanisms may be at play. Similarly, some interventions used in the primary AF setting have a very different risk:benefit ratio when considered in the postoperative period, for example, the initiation of anticoagulation. A deeper understanding of post-cardiac surgery-specific factors predisposing, triggering, and sustaining AFACS will allow for more targeted trials examining prevention strategies and treatment priorities for this patient group.

\section{Conclusions}

AFACS is the most common adverse event after cardiac surgery and is associated with significant morbidity, mortality, and cost. It is unlikely that there is a single unifying mechanism for development of this arrhythmia and current studies point to the high likelihood of multiple disparate pathways leading to the common outcome of AFACS. Supported by studies with high levels of evidence, multiple societal guidelines have made recommendations supporting the use of prophylactic and treatment interventions. It remains uncertain whether the relationship between AFACS and poorer outcomes is causative. Well-designed future studies in the field should aspire to clarify the effects of their short-term interventions on longer-term outcome measures.

Development of a validated risk-stratification model would help to appropriately target protocols for prevention of AFACS, minimizing some of the non-trivial risks of either AFACS itself, or routinely used preventative measures.

Funding Information Ben O'Brien has received research funding from Correvio Pharma (Vernakalant Practice Evaluation) and the British Heart Foundation (Tight K study).

\section{Compliance with Ethical Standards}

Conflict of Interest Peter S. Burrage declares that he has no conflict of interest.

Ying H. Low declares that she has no conflict of interest.

Niall G. Campbell declares that he has no conflict of interest.

Human and Animal Rights and Informed Consent This article does not contain any studies with human or animal subjects performed by any of the authors.

Open Access This article is distributed under the terms of the Creative Commons Attribution 4.0 International License (http:// creativecommons.org/licenses/by/4.0/), which permits unrestricted use, distribution, and reproduction in any medium, provided you give appropriate credit to the original author(s) and the source, provide a link to the Creative Commons license, and indicate if changes were made.

\section{References}

Papers of particular interest, published recently, have been highlighted as:

- Of importance

-• Of major importance

1. D'Agostino RS, Jacobs JP, Badhwar V, Fernandez FG, Paone G, Wormuth DW, et al. The Society of Thoracic Surgeons adult cardiac surgery database: 2018 update on outcomes and quality. Ann Thorac Surg. 2018;105(1):15-23. https://doi.org/10.1016/j. athoracsur.2017.10.035. 
2. Shen J, Lall S, Zheng V, Buckley P, Damiano RJ Jr, Schuessler RB. The persistent problem of new-onset postoperative atrial fibrillation: a single-institution experience over two decades. J Thorac Cardiovasc Surg. 2011;141(2):559-70. https://doi.org/10. 1016/j.jtcvs.2010.03.011.

3. D'Agostino RS, Jacobs JP, Badhwar V, Paone G, Rankin JS, Han $\mathrm{JM}$, et al. The society of thoracic surgeons adult cardiac surgery database: 2016 update on outcomes and quality. Ann Thorac Surg. 2016;101(1):24-32. https://doi.org/10.1016/j.athoracsur.2015.11. 032 .

4. Philip I, Berroeta C, Leblanc I. Perioperative challenges of atrial fibrillation. Curr Opin Anaesthesiol. 2014;27(3):344-52. https:// doi.org/10.1097/ACO.0000000000000070.

5. Frendl G, Sodickson AC, Chung MK, Waldo AL, Gersh BJ, Tisdale JE, et al. 2014 AATS guidelines for the prevention and management of perioperative atrial fibrillation and flutter for thoracic surgical procedures. J Thorac Cardiovasc Surg. 2014;148(3): e153-93. https://doi.org/10.1016/j.jtcvs.2014.06.036.

6. Almassi GH, Schowalter T, Nicolosi AC, Aggarwal A, Moritz TE, Henderson WG, et al. Atrial fibrillation after cardiac surgery: a major morbid event? Ann Surg. 1997;226(4):501-11 discussion 11-3.

7. Mathew JP, Fontes ML, Tudor IC, Ramsay J, Duke P, Mazer CD, et al. A multicenter risk index for atrial fibrillation after cardiac surgery. Jama. 2004;291(14):1720-9. https://doi.org/10.1001/ jama.291.14.1720.

8. Kalavrouziotis D, Buth KJ, Ali IS. The impact of new-onset atrial fibrillation on in-hospital mortality following cardiac surgery. Chest. 2007;131(3):833-9. https://doi.org/10.1378/chest.06-0735.

9. LaPar DJ, Speir AM, Crosby IK, Fonner E Jr, Brown M, Rich JB, et al. Postoperative atrial fibrillation significantly increases mortality, hospital readmission, and hospital costs. Ann Thorac Surg. 2014;98(2):527-33; discussion 33. https://doi.org/10.1016/j. athoracsur.2014.03.039.

10. Almassi GH, Wagner TH, Carr B, Hattler B, Collins JF, Quin JA, et al. Postoperative atrial fibrillation impacts on costs and one-year clinical outcomes: the Veterans Affairs Randomized On/Off Bypass Trial. Ann Thorac Surg. 2015;99(1):109-14. https://doi. org/10.1016/j.athoracsur.2014.07.035.

11. Steinberg BA, Zhao Y, He X, Hernandez AF, Fullerton DA, Thomas KL, et al. Management of postoperative atrial fibrillation and subsequent outcomes in contemporary patients undergoing cardiac surgery: insights from the Society of Thoracic Surgeons CAPS-Care Atrial Fibrillation Registry. Clin Cardiol. 2014;37(1): 7-13. https://doi.org/10.1002/clc.22230.

12. Benjamin EJ, Levy D, Vaziri SM, D'Agostino RB, Belanger AJ, Wolf PA. Independent risk factors for atrial fibrillation in a population-based cohort. The Framingham Heart Study. JAMA. 1994;271(11):840-4

13. Echahidi N, Pibarot P, O'Hara G, Mathieu P. Mechanisms, prevention, and treatment of atrial fibrillation after cardiac surgery. J Am Coll Cardiol. 2008;51(8):793-801. https://doi.org/10.1016/j.jacc. 2007.10.043.

14. Kim MH, Johnston SS, Chu BC, Dalal MR, Schulman KL. Estimation of total incremental health care costs in patients with atrial fibrillation in the United States. Circ Cardiovasc Qual Outcomes. 2011;4(3):313-20. https://doi.org/10.1161/ CIRCOUTCOMES.110.958165.

15. Wolowacz SE, Samuel M, Brennan VK, Jasso-Mosqueda JG, Van Gelder IC. The cost of illness of atrial fibrillation: a systematic review of the recent literature. Europace. 2011;13(10):1375-85. https://doi.org/10.1093/europace/eur194.

16. Greenberg JW, Lancaster TS, Schuessler RB, Melby SJ. Postoperative atrial fibrillation following cardiac surgery: a persistent complication. Eur J Cardiothorac Surg. 2017;52(4):66572. https://doi.org/10.1093/ejcts/ezx039.
17. Toivonen L, Kadish A, Kou W, Morady F. Determinants of the ventricular rate during atrial fibrillation. J Am Coll Cardiol. 1990;16(5):1194-200.

18. Calkins H, Kuck KH, Cappato R, Brugada J, Camm AJ, Chen SA, et al. $2012 \mathrm{HRS} / \mathrm{EHRA} / \mathrm{ECAS}$ expert consensus statement on catheter and surgical ablation of atrial fibrillation: recommendations for patient selection, procedural techniques, patient management and follow-up, definitions, endpoints, and research trial design: a report of the Heart Rhythm Society (HRS) Task Force on Catheter and Surgical Ablation of Atrial Fibrillation. Developed in partnership with the European Heart Rhythm Association (EHRA), a registered branch of the European Society of Cardiology (ESC) and the European Cardiac Arrhythmia Society (ECAS); and in collaboration with the American College of Cardiology (ACC), American Heart Association (AHA), the Asia Pacific Heart Rhythm Society (APHRS), and the Society of Thoracic Surgeons (STS). Endorsed by the governing bodies of the American College of Cardiology Foundation, the American Heart Association, the European Cardiac Arrhythmia Society, the European Heart Rhythm Association, the Society of Thoracic Surgeons, the Asia Pacific Heart Rhythm Society, and the Heart Rhythm Society. Heart Rhythm. 2012;9(4):632-96 e21. https://doi.org/10.1016/j.hrthm.2011.12.016.

19. Ferrari R, Bertini M, Blomstrom-Lundqvist C, Dobrev D, Kirchhof P, Pappone C, et al. An update on atrial fibrillation in 2014: from pathophysiology to treatment. Int J Cardiol. 2016;203: 22-9. https://doi.org/10.1016/j.ijcard.2015.10.089.

20. Iwasaki YK, Nishida K, Kato T, Nattel S. Atrial fibrillation pathophysiology: implications for management. Circulation. 2011;124(20):2264-74. https://doi.org/10.1161/ CIRCULATIONAHA.111.019893.

21. Chard M, Tabrizchi R. The role of pulmonary veins in atrial fibrillation: a complex yet simple story. Pharmacol Ther. 2009;124(2): 207-18. https://doi.org/10.1016/j.pharmthera.2009.07.002.

22. Vaitkevicius R, Saburkina I, Rysevaite K, Vaitkeviciene I, Pauziene N, Zaliunas R, et al. Nerve supply of the human pulmonary veins: an anatomical study. Heart Rhythm. 2009;6(2):221-8. https://doi.org/10.1016/j.hrthm.2008.10.027.

23. Nattel S, Burstein B, Dobrev D. Atrial remodeling and atrial fibrillation: mechanisms and implications. Circ Arrhythm Electrophysiol. 2008;1(1):62-73. https://doi.org/10.1161/ CIRCEP.107.754564.

24. Voigt N, Heijman J, Wang Q, Chiang DY, Li N, Karck M, et al. Cellular and molecular mechanisms of atrial arrhythmogenesis in patients with paroxysmal atrial fibrillation. Circulation. 2014;129(2):145-56. https://doi.org/10.1161/ CIRCULATIONAHA.113.006641.

25. Tchervenkov CI, Wynands JE, Symes JF, Malcolm ID, Dobell AR, Morin JE. Persistent atrial activity during cardioplegic arrest: a possible factor in the etiology of postoperative supraventricular tachyarrhythmias. Ann Thorac Surg. 1983;36(4):437-43.

26. Melby SJ, George JF, Picone DJ, Wallace JP, Davies JE, George DJ, et al. A time-related parametric risk factor analysis for postoperative atrial fibrillation after heart surgery. J Thorac Cardiovasc Surg. 2015;149(3):886-92. https://doi.org/10.1016/j.jtcvs.2014. 11.032 .

27. Banach M, Rysz J, Drozdz JA, Okonski P, Misztal M, Barylski M, et al. Risk factors of atrial fibrillation following coronary artery bypass grafting: a preliminary report. Circ J. 2006;70(4):438-41.

28. Wong JK, Lobato RL, Pinesett A, Maxwell BG, Mora-Mangano CT, Perez MV. P-wave characteristics on routine preoperative electrocardiogram improve prediction of new-onset postoperative atrial fibrillation in cardiac surgery. J Cardiothorac Vasc Anesth. 2014;28(6):1497-504. https://doi.org/10.1053/j.jvca.2014.04. 034. 
29. Aytemir K, Aksoyek S, Ozer N, Aslamaci S, Oto A. Atrial fibrillation after coronary artery bypass surgery: $\mathrm{P}$ wave signal averaged ECG, clinical and angiographic variables in risk assessment. Int J Cardiol. 1999;69(1):49-56.

30. Amat-Santos IJ, Rodes-Cabau J, Urena M, DeLarochelliere R, Doyle D, Bagur R, et al. Incidence, predictive factors, and prognostic value of new-onset atrial fibrillation following transcatheter aortic valve implantation. J Am Coll Cardiol. 2012;59(2):178-88. https://doi.org/10.1016/j.jacc.2011.09.061.

31. Mahoney EM, Thompson TD, Veledar E, Williams J, Weintraub WS. Cost-effectiveness of targeting patients undergoing cardiac surgery for therapy with intravenous amiodarone to prevent atrial fibrillation. J Am Coll Cardiol. 2002;40(4):737-45.

32. Orlowska-Baranowska E, Baranowski R, Michalek P, Hoffman P, Rywik T, Rawczylska-Englert I. Prediction of paroxysmal atrial fibrillation after aortic valve replacement in patients with aortic stenosis: identification of potential risk factors. J Heart Valve Dis. 2003;12(2): 136-41

33. Wiggins MC, Firpi HA, Blanco RR, Amer M, Dudley SC. Prediction of atrial fibrillation following cardiac surgery using rough set derived rules. Conf Proc IEEE Eng Med Biol Soc. 2006;1:4006-9. https://doi.org/10.1109/IEMBS.2006.259834.

34. Magee MJ, Herbert MA, Dewey TM, Edgerton JR, Ryan WH, Prince $\mathrm{S}$, et al. Atrial fibrillation after coronary artery bypass grafting surgery: development of a predictive risk algorithm. Ann Thorac Surg. 2007;83(5):1707-12; discussion 12. https:// doi.org/10.1016/j.athoracsur.2006.12.032.

35. Lip GY, Nieuwlaat R, Pisters R, Lane DA, Crijns HJ. Refining clinical risk stratification for predicting stroke and thromboembolism in atrial fibrillation using a novel risk factor-based approach: the euro heart survey on atrial fibrillation. Chest. 2010;137(2): 263-72. https://doi.org/10.1378/chest.09-1584.

36. Silva RG, Lima GG, Guerra N, Bigolin AV, Petersen LC. Risk index proposal to predict atrial fibrillation after cardiac surgery. Rev Bras Cir Cardiovasc. 2010;25(2):183-9.

37. Karaca M, Demirbas MI, Biceroglu S, Cevik A, Cetin Y, Arpaz M, et al. Prediction of early postoperative atrial fibrillation after cardiac surgery: is it possible? Cardiovasc J Afr. 2012;23(1):34-6. https://doi.org/10.5830/CVJA-2011-010.

38. Helgadottir S, Sigurdsson MI, Ingvarsdottir IL, Arnar DO, Gudbjartsson T. Atrial fibrillation following cardiac surgery: risk analysis and long-term survival. J Cardiothorac Surg. 2012;7:87. https://doi.org/10.1186/1749-8090-7-87.

39. Chua SK, Shyu KG, Lu MJ, Lien LM, Lin CH, Chao HH, et al. Clinical utility of CHADS2 and CHA2DS2-VASc scoring systems for predicting postoperative atrial fibrillation after cardiac surgery. J Thorac Cardiovasc Surg. 2013;146(4):919-26 e1. https://doi.org/10.1016/j.jtcvs.2013.03.040.

40. Mariscalco G, Biancari F, Zanobini M, Cottini M, Piffaretti G, Saccocci M, et al. Bedside tool for predicting the risk of postoperative atrial fibrillation after cardiac surgery: the POAF score. $\mathrm{J}$ Am Heart Assoc. 2014;3(2):e000752. https://doi.org/10.1161/ JAHA.113.000752.

41. Borde D, Gandhe U, Hargave N, Pandey K, Mathew M, Joshi S. Prediction of postoperative atrial fibrillation after coronary artery bypass grafting surgery: is CHA 2 DS 2 -VASc score useful? Ann Card Anaesth. 2014;17(3):182-7. https://doi.org/10.4103/09719784.135841

42. Kolek MJ, Muehlschlegel JD, Bush WS, Parvez B, Murray KT, Stein CM, et al. Genetic and clinical risk prediction model for postoperative atrial fibrillation. Circ Arrhythm Electrophysiol. 2015;8(1):25-31. https://doi.org/10.1161/CIRCEP.114.002300.

43. Yin L, Ling X, Zhang Y, Shen H, Min J, Xi W, et al. CHADS2 and CHA2DS2-VASc scoring systems for predicting atrial fibrillation following cardiac valve surgery. PLoS One. 2015;10(4): e0123858. https://doi.org/10.1371/journal.pone.0123858.
44. Tran DT, Perry JJ, Dupuis JY, Elmestekawy E, Wells GA. Predicting new-onset postoperative atrial fibrillation in cardiac surgery patients. J Cardiothorac Vasc Anesth. 2015;29(5):111726. https://doi.org/10.1053/j.jvca.2014.12.012.

45. Zhang W, Liu W, Chew ST, Shen L, Ti LK. A clinical prediction model for postcardiac surgery atrial fibrillation in an Asian population. Anesth Analg. 2016;123(2):283-9. https://doi.org/10.1213/ ANE.0000000000001384.

46. Cameron MJ, Tran DTT, Abboud J, Newton EK, Rashidian H, Dupuis JY. Prospective external validation of three preoperative risk scores for prediction of new onset atrial fibrillation after cardiac surgery. Anesth Analg. 2018;126(1):33-8. https://doi.org/10. 1213/ANE.0000000000002112.

47.• Muehlschlegel JD, Burrage PS, Ngai JY, Prutkin JM, Huang CC, $\mathrm{Xu} \mathrm{X}$, et al. Society of Cardiovascular Anesthesiologists/ European Association of Cardiothoracic Anaesthetists Practice Advisory for the Management of Perioperative Atrial Fibrillation in Patients Undergoing Cardiac Surgery. Anesth Analg. 2019;128(1):33-42. https://doi.org/10.1213/ANE. 0000000000003865 Most recent analysis and summation of current multi-society post-cardiac surgery atrial fibrillation guidelines, includes graphical advisory tool.

48.• O'Brien B, Burrage PS, Ngai JY, Prutkin JM, Huang CC, Xu X, et al. Society of Cardiovascular Anesthesiologists/European Association of Cardiothoracic Anaesthetists Practice Advisory for the Management of Perioperative Atrial Fibrillation in Patients Undergoing Cardiac Surgery. J Cardiothorac Vasc Anesth. 2019;33(1):12-26. https://doi.org/10.1053/j.jvca.2018. 09.039 Most recent analysis and summation of current multisociety post-cardiac surgery atrial fibrillation guidelines, includes graphical advisory tool.

49.• Arsenault KA, Yusuf AM, Crystal E, Healey JS, Morillo CA, Nair $\mathrm{GM}$ et al. Interventions for preventing post-operative atrial fibrillation in patients undergoing heart surgery. The Cochrane database of systematic reviews. 2013;(1):Cd003611. doi:https://doi.org/10. 1002/14651858.CD003611.pub3. Comprenhensive metaanalysis of efficacy of both pharmacologic and nonpharmacologic interventions on incidence of atrial fibrillation as well as effect on secondary outcomes such as stroke, LOS and cost.

50. Campbell NG, Allen E, Sanders J, Swinson R, Birch S, Sturgess J, et al. The impact of maintaining serum potassium $\geq 3.6 \mathrm{mEq} / \mathrm{L}$ vs $\geq 4.5 \mathrm{mEq} / \mathrm{L}$ on the incidence of new-onset atrial fibrillation in the first 120 hours after isolated elective coronary artery bypass grafting - study protocol for a randomised feasibility trial for the proposed Tight $\mathrm{K}$ randomized non-inferiority trial. Trials. 2017;18(1):618. https://doi.org/10.1186/s13063-017-2349-x.

51. Dunning J, Treasure T, Versteegh M, Nashef SA. Guidelines on the prevention and management of de novo atrial fibrillation after cardiac and thoracic surgery. Eur J Cardiothorac Surg. 2006;30(6): 852-72. https://doi.org/10.1016/j.ejcts.2006.09.003.

52. Burgess DC, Kilborn MJ, Keech AC. Interventions for prevention of post-operative atrial fibrillation and its complications after cardiac surgery: a meta-analysis. Eur Heart J. 2006;27(23):2846-57. https://doi.org/10.1093/eurheartj/ehl272.

53. Thein PM, White K, Banker K, Lunny C, Mirzaee S, Nasis A. Preoperative use of oral beta-adrenergic blocking agents and the incidence of new-onset atrial fibrillation after cardiac surgery. A systematic review and meta-analysis. Heart Lung Circ. 2018;27(3):310-21. https://doi.org/10.1016/j.hlc.2017.08.026.

54. Tamura T, Yatabe T, Yokoyama M. Prevention of atrial fibrillation after cardiac surgery using low-dose landiolol: a systematic review and meta-analysis. J Clin Anesth. 2017;42:1-6. https://doi.org/10. 1016/j.jclinane.2017.07.009.

55. Ji T, Feng C, Sun L, Ye X, Bai Y, Chen Q, et al. Are beta-blockers effective for preventing post-coronary artery bypass grafting atrial 
fibrillation? Direct and network meta-analyses. Ir J Med Sci. 2016;185(2):503-11. https://doi.org/10.1007/s11845-016-1447-1.

56. Sakamoto A, Hamasaki T, Kitakaze M. Perioperative landiolol administration reduces atrial fibrillation after cardiac surgery: a meta-analysis of randomized controlled trials. Adv Ther. 2014;31(4):440-50. https://doi.org/10.1007/s12325-014-0116-x.

57. Wang HS, Wang ZW, Yin ZT. Carvedilol for prevention of atrial fibrillation after cardiac surgery: a meta-analysis. PLoS One. 2014;9(4):e94005. https://doi.org/10.1371/journal.pone.0094005.

58. Liu S, Bian C, Zhang Y, Jian Y, Liu W. Landiolol hydrochloride for prevention of atrial fibrillation after cardiac surgery: a metaanalysis. Pacing Clin Electrophysiol. 2014;37(6):691-6. https:// doi.org/10.1111/pace.12379.

59. Fuster V, Ryden LE, Cannom DS, Crijns HJ, Curtis AB, Ellenbogen KA, et al. 2011 ACCF/AHA/HRS focused updates incorporated into the ACC/AHA/ESC 2006 Guidelines for the management of patients with atrial fibrillation: a report of the American College of Cardiology Foundation/American Heart Association Task Force on Practice Guidelines developed in partnership with the European Society of Cardiology and in collaboration with the European Heart Rhythm Association and the Heart Rhythm Society. J Am Coll Cardiol. 2011;57(11):e101-98. https://doi.org/10.1016/j.jacc.2010.09.013.

60. Kirchhof P, Benussi S, Kotecha D, Ahlsson A, Atar D, Casadei B, et al. 2016 ESC Guidelines for the management of atrial fibrillation developed in collaboration with EACTS. Rev Esp Cardiol (Engl Ed). 2017;70(1):50. https://doi.org/10.1016/j.rec.2016.11. 033.

61. Hillis LD, Smith PK, Anderson JL, Bittl JA, Bridges CR, Byrne JG, et al. Special Articles: 2011 ACCF/AHA Guideline for Coronary Artery Bypass Graft Surgery: executive summary: a report of the American College of Cardiology Foundation/ American Heart Association Task Force on Practice Guidelines. Anesth Analg. 2012;114(1):11-45. https://doi.org/10.1213/ANE. 0b013e3182407c25.

62. Bagshaw SM, Galbraith PD, Mitchell LB, Sauve R, Exner DV, Ghali WA. Prophylactic amiodarone for prevention of atrial fibrillation after cardiac surgery: a meta-analysis. Ann Thorac Surg. 2006;82(5):1927-37.

63. Aasbo JD, Lawrence AT, Krishnan K, Kim MH, Trohman RG. Amiodarone prophylaxis reduces major cardiovascular morbidity and length of stay after cardiac surgery: a meta-analysis. Ann Intern Med. 2005;143(5):327-36.

64. Gillespie EL, Coleman CI, Sander S, Kluger J, Gryskiewicz KA, White CM. Effect of prophylactic amiodarone on clinical and economic outcomes after cardiothoracic surgery: a meta-analysis. Ann Pharmacother. 2005;39(9):1409-15. https://doi.org/10.1345/ aph.1E592.

65. Chatterjee S, Sardar P, Mukherjee D, Lichstein E, Aikat S. Timing and route of amiodarone for prevention of postoperative atrial fibrillation after cardiac surgery: a network regression meta-analysis. Pacing Clin Electrophysiol. 2013;36(8):1017-23. https://doi. org/10.1111/pace.12140.

66. Zhu J, Wang C, Gao D, Zhang C, Zhang Y, Lu Y, et al. Metaanalysis of amiodarone versus beta-blocker as a prophylactic therapy against atrial fibrillation following cardiac surgery. Intern Med J. 2012;42(10):1078-87. https://doi.org/10.1111/j.1445-5994. 2012.02844.x.

67. Buckley MS, Nolan PE Jr, Slack MK, Tisdale JE, Hilleman DE, Copeland JG. Amiodarone prophylaxis for atrial fibrillation after cardiac surgery: meta-analysis of dose response and timing of initiation. Pharmacotherapy. 2007;27(3):360-8. https://doi.org/ 10.1592/phco.27.3.360.

68. Somberg J, Molnar J. Sotalol versus amiodarone in treatment of atrial fibrillation. J Atr Fibrillation. 2016;8(5):1359. https://doi. org/10.4022/jafib.1359.
69. Kerin NZ, Jacob S. The efficacy of sotalol in preventing postoperative atrial fibrillation: a meta-analysis. Am J Med. 2011;124(9): 875 e1-9. https://doi.org/10.1016/j.amjmed.2011.04.025.

70. Wurdeman RL, Mooss AN, Mohiuddin SM, Lenz TL. Amiodarone vs. sotalol as prophylaxis against atrial fibrillation/ flutter after heart surgery: a meta-analysis. Chest. 2002;121(4): 1203-10.

71. Gorenek B, Pelliccia A, Benjamin EJ, Boriani G, Crijns HJ, Fogel RI, et al. European Heart Rhythm Association (EHRA)/European Association of Cardiovascular Prevention and Rehabilitation (EACPR) position paper on how to prevent atrial fibrillation endorsed by the Heart Rhythm Society (HRS) and Asia Pacific Heart Rhythm Society (APHRS). Europace. 2017;19(2):190-225. https://doi.org/10.1093/europace/euw242.

72. Patel N, Kluger J. Ranolazine for prevention of atrial fibrillation after cardiac surgery: a systematic review. Cureus. 2018;10(5): e2584. https://doi.org/10.7759/cureus.2584.

73. Trivedi C, Upadhyay A, Solanki K. Efficacy of ranolazine in preventing atrial fibrillation following cardiac surgery: results from a meta-analysis. J Arrhythm. 2017;33(3):161-6. https://doi. org/10.1016/j.joa.2016.10.563.

74. Cappabianca G, Rotunno C, de Luca Tupputi Schinosa L, Ranieri VM, Paparella D. Protective effects of steroids in cardiac surgery: a meta-analysis of randomized double-blind trials. J Cardiothorac Vasc Anesth. 2011;25(1):156-65. https://doi.org/10.1053/j.jvca. 2010.03.015

75. Marik PE, Fromm R. The efficacy and dosage effect of corticosteroids for the prevention of atrial fibrillation after cardiac surgery: a systematic review. J Crit Care. 2009;24(3):458-63. https://doi.org/ 10.1016/j.jcrc.2008.10.016.

76. Dvirnik N, Belley-Cote EP, Hanif H, Devereaux PJ, Lamy A, Dieleman JM, et al. Steroids in cardiac surgery: a systematic review and meta-analysis. Br J Anaesth. 2018;120(4):657-67. https://doi.org/10.1016/j.bja.2017.10.025.

77. Cheruku KK, Ghani A, Ahmad F, Pappas P, Silverman PR, Zelinger A, et al. Efficacy of nonsteroidal anti-inflammatory medications for prevention of atrial fibrillation following coronary artery bypass graft surgery. Prev Cardiol. 2004;7(1):13-8.

78. Horbach SJ, Lopes RD, da CGJC MF, Mehta RH, Petracco JB, et al. Naproxen as prophylaxis against atrial fibrillation after cardiac surgery: the NAFARM randomized trial. Am J Med. 2011;124(11):1036-42. https://doi.org/10.1016/j.amjmed.2011. 07.026 .

79. Papageorgiou N, Briasoulis A, Lazaros G, Imazio M, Tousoulis D. Colchicine for prevention and treatment of cardiac diseases: A meta-analysis. Cardiovasc Ther. 2017;35(1):10-8. https://doi.org/ 10.1111/1755-5922.12226.

80. Salih M, Smer A, Charnigo R, Ayan M, Darrat YH, Traina M, et al. Colchicine for prevention of post-cardiac procedure atrial fibrillation: Meta-analysis of randomized controlled trials. Int $\mathrm{J}$ Cardiol. 2017;243:258-62. https://doi.org/10.1016/j.ijcard.2017. 04.022 .

81. Verma S, Eikelboom JW, Nidorf SM, Al-Omran M, Gupta N, Teoh H, et al. Colchicine in cardiac disease: a systematic review and meta-analysis of randomized controlled trials. BMC Cardiovasc Disord. 2015;15:96. https://doi.org/10.1186/s12872015-0068-3.

82. Trivedi C, Sadadia M. Colchicine in prevention of atrial fibrillation following cardiac surgery: systematic review and meta-analysis. Indian J Pharm. 2014;46(6):590-5. https://doi.org/10.4103/ 0253-7613.144905.

83. Lennerz C, Barman M, Tantawy M, Sopher M, Whittaker P. Colchicine for primary prevention of atrial fibrillation after open-heart surgery: Systematic review and meta-analysis. Int J Cardiol. 2017;249:127-37. https://doi.org/10.1016/j.ijcard.2017. 08.039 . 
84. Putzu A, Capelli B, Belletti A, Cassina T, Ferrari E, Gallo M, et al. Perioperative statin therapy in cardiac surgery: a meta-analysis of randomized controlled trials. Crit Care. 2016;20(1):395. https:// doi.org/10.1186/s13054-016-1560-6.

85. Kuhn EW, Liakopoulos OJ, Stange S, Deppe AC, Slottosch I, Choi $\mathrm{YH}$, et al. Preoperative statin therapy in cardiac surgery: a meta-analysis of 90,000 patients. Eur J Cardiothorac Surg. 2014;45(1):17-26; discussion. https://doi.org/10.1093/ejcts/ ezt181.

86. Zhang B, Zhen Y, Tao A, Bao Z, Zhang G. Polyunsaturated fatty acids for the prevention of atrial fibrillation after cardiac surgery: an updated meta-analysis of randomized controlled trials. J Cardiol. 2014;63(1):53-9. https://doi.org/10.1016/j.jjcc.2013.06. 014 .

87. Langlois PL, Hardy G, Manzanares W. Omega-3 polyunsaturated fatty acids in cardiac surgery patients: An updated systematic review and meta-analysis. Clin Nutr. 2017;36(3):737-46. https:// doi.org/10.1016/j.clnu.2016.05.013.

88. Wang H, Chen J, Zhao L. N-3 polyunsaturated fatty acids for prevention of postoperative atrial fibrillation: updated metaanalysis and systematic review. J Interv Card Electrophysiol. 2018;51(2):105-15. https://doi.org/10.1007/s10840-018-0315-5.

89. Ali-Hasan-Al-Saegh S, Mirhosseini SJ, Tahernejad M, Mahdavi P, Shahidzadeh A, Karimi-Bondarabadi AA, et al. Impact of antioxidant supplementations on cardio-renal protection in cardiac surgery: an updated and comprehensive meta-analysis and systematic review. Cardiovasc Ther. 2016;34(5):360-70. https://doi.org/10. 1111/1755-5922.12207.

90. Mariani J, Doval HC, Nul D, Varini S, Grancelli H, Ferrante D, et al. N-3 polyunsaturated fatty acids to prevent atrial fibrillation: updated systematic review and meta-analysis of randomized controlled trials. J Am Heart Assoc. 2013;2(1):e005033. https://doi. org/10.1161/JAHA.112.005033.

91. Harrison RW, Hasselblad V, Mehta RH, Levin R, Harrington RA, Alexander JH. Effect of levosimendan on survival and adverse events after cardiac surgery: a meta-analysis. J Cardiothorac Vasc Anesth. 2013;27(6):1224-32. https://doi.org/10.1053/j.jvca. 2013.03.027.

92. Wang B, He X, Gong Y, Cheng B. Levosimendan in Patients with Left Ventricular Dysfunction Undergoing Cardiac Surgery: An Update Meta-Analysis and Trial Sequential Analysis. Biomed Res Int. 2018;2018:7563083. https://doi.org/10.1155/2018/ 7563083.

93. Ali-Hassan-Sayegh S, Mirhosseini SJ, Rezaeisadrabadi M, Dehghan HR, Sedaghat-Hamedani F, Kayvanpour E, et al. Antioxidant supplementations for prevention of atrial fibrillation after cardiac surgery: an updated comprehensive systematic review and meta-analysis of 23 randomized controlled trials. Interact Cardiovasc Thorac Surg. 2014;18(5):646-54. https://doi. org/10.1093/icvts/ivu020.

94. Liu XH, Xu CY, Fan GH. Efficacy of N-acetylcysteine in preventing atrial fibrillation after cardiac surgery: a metaanalysis of published randomized controlled trials. BMC Cardiovasc Disord. 2014;14:52. https://doi.org/10.1186/14712261-14-52.

95. Gu WJ, Wu ZJ, Wang PF, Aung LH, Yin RX. N-Acetylcysteine supplementation for the prevention of atrial fibrillation after cardiac surgery: a meta-analysis of eight randomized controlled trials. BMC Cardiovasc Disord. 2012;12:10. https://doi.org/10.1186/ 1471-2261-12-10.

96. Shi R, Li ZH, Chen D, Wu QC, Zhou XL, Tie HT. Sole and combined vitamin $\mathrm{C}$ supplementation can prevent postoperative atrial fibrillation after cardiac surgery: a systematic review and meta-analysis of randomized controlled trials. Clin Cardiol. 2018;41(6):871-8. https://doi.org/10.1002/clc.22951.
97. Hemila H, Suonsyrja T. Vitamin C for preventing atrial fibrillation in high risk patients: a systematic review and meta-analysis. BMC Cardiovasc Disord. 2017;17(1):49. https://doi.org/10.1186/ s12872-017-0478-5.

98. Hu X, Yuan L, Wang H, Li C, Cai J, Hu Y, et al. Efficacy and safety of vitamin $\mathrm{C}$ for atrial fibrillation after cardiac surgery: a meta-analysis with trial sequential analysis of randomized controlled trials. Int J Surg. 2017;37:58-64. https://doi.org/10.1016/ j.ijsu.2016.12.009.

99. Baker WL, Coleman CI. Meta-analysis of ascorbic acid for prevention of postoperative atrial fibrillation after cardiac surgery. Am J Health Syst Pharm. 2016;73(24):2056-66. https://doi.org/ 10.2146/ajhp160066.

100. Hajjar LA, Vincent JL, Barbosa Gomes Galas FR, Rhodes A, Landoni G, Osawa EA, et al. Vasopressin versus Norepinephrine in Patients with Vasoplegic Shock after Cardiac Surgery: The VANCS Randomized Controlled Trial. Anesthesiology. 2017;126(1):85-93. https://doi.org/10.1097/aln. 0000000000001434 .

101. Biancari F, Mahar MA. Meta-analysis of randomized trials on the efficacy of posterior pericardiotomy in preventing atrial fibrillation after coronary artery bypass surgery. J Thorac Cardiovasc Surg. 2010;139(5):1158-61. https://doi.org/10.1016/j.jtcvs.2009.07. 012.

102. Hu XL, Chen Y, Zhou ZD, Ying J, Hu YH, Xu GH. Posterior pericardiotomy for the prevention of atrial fibrillation after coronary artery bypass grafting: A meta-analysis of randomized controlled trials. Int J Cardiol. 2016;215:252-6. https://doi.org/10. 1016/j.ijcard.2016.04.081.

103. Cummings JE, Gill I, Akhrass R, Dery M, Biblo LA, Quan KJ. Preservation of the anterior fat pad paradoxically decreases the incidence of postoperative atrial fibrillation in humans. J Am Coll Cardiol. 2004;43(6):994-1000. https://doi.org/10.1016/j. jacc.2003.07.055.

104. Liu S, Jing Y, Zhang J, Bian C, Zhang YU, Zhang X. Does Anterior Fat Pad Removal Reduce the Incidence of Atrial Fibrillation after CABG? A Meta-Analysis of Randomized Controlled Trials. Pacing Clin Electrophysiol. 2015;38(11): 1363-8. https://doi.org/10.1111/pace.12740.

105. White CM, Sander S, Coleman CI, Gallagher R, Takata H, Humphrey C, et al. Impact of epicardial anterior fat pad retention on postcardiothoracic surgery atrial fibrillation incidence: the AFIST-III Study. J Am Coll Cardiol. 2007;49(3):298-303. https://doi.org/10.1016/j.jacc.2006.10.033.

106. Pokushalov E, Kozlov B, Romanov A, Strelnikov A, Bayramova $\mathrm{S}$, Sergeevichev D, et al. Botulinum toxin injection in epicardial fat pads can prevent recurrences of atrial fibrillation after cardiac surgery: results of a randomized pilot study. J Am Coll Cardiol. 2014;64(6):628-9. https://doi.org/10.1016/j.jacc.2014.04.062.

107. Romanov A, Pokushalov E, Ponomarev D, Bayramova S, Shabanov V, Losik D, et al. Long-term suppression of atrial fibrillation by botulinum toxin injection into epicardial fat pads in patients undergoing cardiac surgery: three-year follow-up of a randomized study. Heart Rhythm. 2018. https://doi.org/10.1016/ j.hrthm.2018.08.019.

108. Pokushalov E, Kozlov B, Romanov A, Strelnikov A, Bayramova S, Sergeevichev D, et al. Long-term suppression of atrial fibrillation by botulinum toxin injection into epicardial fat pads in patients undergoing cardiac surgery: one-year follow-up of a randomized pilot study. Circ Arrhythm Electrophysiol. 2015;8(6): 1334-41. https://doi.org/10.1161/circep.115.003199.

109. Waldron NH, Cooter M, Haney JC, Schroder JN, Gaca JG, Lin SS, et al. Temporary autonomic modulation with botulinum toxin type A to reduce atrial fibrillation after cardiac surgery. Heart Rhythm. 2019;16(2):178-184.https://doi.org/10.1016/j.hrthm.2018.08. 021. 
110. Moller CH, Penninga L, Wetterslev J, Steinbruchel DA, Gluud C. Off-pump versus on-pump coronary artery bypass grafting for ischaemic heart disease. Cochrane Database Syst Rev. 2012;(3): Cd007224. doi:https://doi.org/10.1002/14651858.CD007224. pub2.

111. Boning A, Diegeler A, Hilker M, Zacher M, Reents W, Faerber G, et al. Preoperative atrial fibrillation and outcome in patients undergoing on-pump or off-pump coronary bypass surgery: lessons learned from the GOPCABE trial. Interact Cardiovasc Thorac Surg. 2015;20(1):74-8. https://doi.org/10.1093/icvts/ivu331.

112. Zaman AG, Alamgir F, Richens T, Williams R, Rothman MT, Mills PG. The role of signal averaged $P$ wave duration and serum magnesium as a combined predictor of atrial fibrillation after elective coronary artery bypass surgery. Heart. 1997;77(6):527-31.

113. Lomivorotov VV, Efremov SM, Pokushalov EA, Karaskov AM. New-onset atrial fibrillation after cardiac surgery: pathophysiology, prophylaxis, and treatment. J Cardiothorac Vasc Anesth. 2016;30(1):200-16. https://doi.org/10.1053/j.jvca.2015.08.003.

114. Bessissow A, Khan J, Devereaux PJ, Alvarez-Garcia J, AlonsoCoello P. Postoperative atrial fibrillation in non-cardiac and cardiac surgery: an overview. J Thromb Haemost. 2015;13(Suppl 1): S304-12. https://doi.org/10.1111/jth.12974.

115. Polderman KH, Girbes AR. Severe electrolyte disorders following cardiac surgery: a prospective controlled observational study. Crit Care. 2004;8(6):R459-66. https://doi.org/10.1186/cc2973.

116. Raiten JM, Ghadimi K, Augoustides JG, Ramakrishna H, Patel PA, Weiss SJ, et al. Atrial fibrillation after cardiac surgery: clinical update on mechanisms and prophylactic strategies. J Cardiothorac Vasc Anesth. 2015;29(3):806-16. https://doi.org/10.1053/j.jvca. 2015.01.001

117. Podrid PJ. Potassium and ventricular arrhythmias. Am J Cardiol. 1990;65(10):33E-44E discussion 52E.

118. Hoekstra M, Hessels L, Rienstra M, Yeh L, Lansink AO, Vogelzang M, et al. Computer-guided normal-low versus normal-high potassium control after cardiac surgery: no impact on atrial fibrillation or atrial flutter. Am Heart J. 2016;172:4552. https://doi.org/10.1016/j.ahj.2015.10.020.

119. Gorenek Chair B, Pelliccia Co-Chair A, Benjamin EJ, Boriani G, Crijns HJ, Fogel RI, et al. European Heart Rhythm Association (EHRA)/European Association of Cardiovascular Prevention and Rehabilitation (EACPR) position paper on how to prevent atrial fibrillation endorsed by the Heart Rhythm Society (HRS) and Asia Pacific Heart Rhythm Society (APHRS). Eur J Prev Cardiol. 2017;24(1):4-40. https://doi.org/10.1177/2047487316676037.

120. Hillis LD, Smith PK, Anderson JL, Bittl JA, Bridges CR, Byrne JG, et al. 2011 ACCF/AHA Guideline for Coronary Artery Bypass Graft Surgery. A report of the American College of Cardiology Foundation/American Heart Association Task Force on Practice Guidelines. Developed in collaboration with the American Association for Thoracic Surgery, Society of Cardiovascular Anesthesiologists, and Society of Thoracic Surgeons. J Am Coll Cardiol. 2011;58(24):e123-210. https://doi. org/10.1016/j.jacc.2011.08.009.

121. Sakamoto A, Kitakaze M, Takamoto S, Namiki A, Kasanuki H, Hosoda S. Landiolol, an ultra-short-acting beta(1)-blocker, more effectively terminates atrial fibrillation than diltiazem after open heart surgery: prospective, multicenter, randomized, open-label study (JL-KNIGHT study). Circ J. 2012;76(5):1097-101.

122. Hilleman DE, Hunter CB, Mohiuddin SM, Maciejewski S. Pharmacological management of atrial fibrillation following cardiac surgery. Am J Cardiovasc Drugs. 2005;5(6):361-9. https:// doi.org/10.2165/00129784-200505060-00003.

123. January CT, Wann LS, Alpert JS, Calkins H, Cigarroa JE, Cleveland JC Jr, et al. 2014 AHA/ACC/HRS guideline for the management of patients with atrial fibrillation: a report of the American College of Cardiology/American Heart Association
Task Force on Practice Guidelines and the Heart Rhythm Society. J Am Coll Cardiol. 2014;64(21):e1-76. https://doi.org/ 10.1016/j.jacc.2014.03.022.

124. Freemantle N, Lafuente-Lafuente C, Mitchell S, Eckert L, Reynolds M. Mixed treatment comparison of dronedarone, amiodarone, sotalol, flecainide, and propafenone, for the management of atrial fibrillation. Europace. 2011;13(3):329-45. https://doi. org/10.1093/europace/euq450.

125. Milan DJ, Saul JP, Somberg JC, Molnar J. Efficacy of intravenous and oral sotalol in pharmacologic conversion of atrial fibrillation: a systematic review and meta-analysis. Cardiology. 2017;136(1): 52-60. https://doi.org/10.1159/000447237.

126. Guerra F, Romandini A, Barbarossa A, Belardinelli L, Capucci A. Ranolazine for rhythm control in atrial fibrillation: a systematic review and meta-analysis. Int J Cardiol. 2017;227:284-91. https:// doi.org/10.1016/j.ijcard.2016.11.103.

127. Mooss AN, Wurdeman RL, Mohiuddin SM, Reyes AP, Sugimoto JT, Scott W, et al. Esmolol versus diltiazem in the treatment of postoperative atrial fibrillation/atrial flutter after open heart surgery. Am Heart J. 2000;140(1):176-80. https://doi.org/10.1067/ mhj.2000.106917.

128. Rezaei Y, Gholami-Fesharaki M, Dehghani MR, Arya A, Haghjoo M, Arjmand N. Statin Antiarrhythmic Effect on Atrial Fibrillation in Statin-Naive Patients Undergoing Cardiac Surgery: A MetaAnalysis of Randomized Controlled Trials. J Cardiovasc Pharmacol Ther. 2016;21(2):167-76. https://doi.org/10.1177/ 1074248415602557.

129. Faisal SA, Apatov DA, Ramakrishna H, Weiner MM. Levosimendan in Cardiac Surgery: Evaluating the Evidence. J Cardiothorac Vasc Anesth. 2018. https://doi.org/10.1053/j.jvca. 2018.05.035.

130. Abacilar AF, Dogan OF. Levosimendan use decreases atrial fibrillation in patients after coronary artery bypass grafting: a pilot study. Heart Surg Forum. 2013;16(5):E287-94.

131. Elbadawi A, Elgendy IY, Saad M, Megaly M, Mentias A, Abuzaid AS, et al. Meta-Analysis of Trials on Prophylactic Use of Levosimendan in Patients Undergoing Cardiac Surgery. Ann Thorac Surg. 2018;105(5):1403-10. https://doi.org/10.1016/j. athoracsur.2017.11.027.

132. Soleimani A, Habibi MR, Hasanzadeh Kiabi F, Alipour A, Habibi $\mathrm{V}$, Azizi S, et al. The effect of intravenous $\mathrm{N}$-acetylcysteine on prevention of atrial fibrillation after coronary artery bypass graft surgery: a double-blind, randomised, placebo-controlled trial. Kardiol Pol. 2018;76(1):99-106. https://doi.org/10.5603/KP. a2017.0183.

133. Mirmohammadsadeghi M, Mirmohammadsadeghi A, Mahmoudian M. Preventive Use of Ascorbic Acid For Atrial Fibrillation After Coronary Artery Bypass Graft Surgery. Heart Surg Forum. 2018;21(5):E415-E7. https://doi.org/10.1532/hsf. 1938.

134. Rodrigo R, Korantzopoulos P, Cereceda M, Asenjo R, Zamorano $\mathrm{J}$, Villalabeitia E, et al. A randomized controlled trial to prevent post-operative atrial fibrillation by antioxidant reinforcement. J Am Coll Cardiol. 2013;62(16):1457-65. https://doi.org/10.1016/ j.jacc.2013.07.014.

135. Macle L, Cairns J, Leblanc K, Tsang T, Skanes A, Cox JL, et al. 2016 Focused Update of the Canadian Cardiovascular Society Guidelines for the Management of Atrial Fibrillation. Can J Cardiol. 2016;32(10):1170-85. https://doi.org/10.1016/j.cjca. 2016.07.591.

136. Fan K, Lee KL, Chiu CS, Lee JW, He GW, Cheung D, et al. Effects of biatrial pacing in prevention of postoperative atrial fibrillation after coronary artery bypass surgery. Circulation. 2000;102(7):755-60. 
137. Chung MK. Proarrhythmic effects of post-operative pacing intended to prevent atrial fibrillation: evidence from a clinical trial. Card Electrophysiol Rev. 2003;7(2):143-6.

138. Greenberg MD, Katz NM, Iuliano S, Tempesta BJ, Solomon AJ. Atrial pacing for the prevention of atrial fibrillation after cardiovascular surgery. J Am Coll Cardiol. 2000;35(6):1416-22.

139. Steinberg JS. Postoperative atrial fibrillation: a billion-dollar problem. J Am Coll Cardiol. 2004;6. United States:1001-3.

140. Mathew JP, Parks R, Savino JS, Friedman AS, Koch C, Mangano DT, et al. Atrial fibrillation following coronary artery bypass graft surgery: predictors, outcomes, and resource utilization. MultiCenter Study of Perioperative Ischemia Research Group. Jama. 1996;276(4):300-6.

141. Pokushalov E, Romanov A, Cherniavsky A, Corbucci G, Pak I, Kareva Y, et al. Ablation of paroxysmal atrial fibrillation during coronary artery bypass grafting: 12 months' follow-up through implantable loop recorder. Eur J Cardiothorac Surg. 2011;40(2): 405-11. https://doi.org/10.1016/j.ejcts.2010.11.083.

142. Cherniavsky A, Kareva Y, Pak I, Rakhmonov S, Pokushalov E, Romanov A, et al. Assessment of results of surgical treatment for persistent atrial fibrillation during coronary artery bypass grafting using implantable loop recorders. Interact Cardiovasc Thorac Surg. 2014;18(6):727-31. https://doi.org/10.1093/icvts/ivu016.

143. Pokushalov E, Romanov A, Corbucci G, Cherniavsky A, Karaskov A. Benefit of ablation of first diagnosed paroxysmal atrial fibrillation during coronary artery bypass grafting: a pilot study. Eur J Cardiothorac Surg. 2012;41(3):556-60. https://doi. org/10.1093/ejcts/ezr101.

144. Blomstrom-Lundqvist C, Johansson B, Berglin E, Nilsson L, Jensen SM, Thelin S, et al. A randomized double-blind study of epicardial left atrial cryoablation for permanent atrial fibrillation in patients undergoing mitral valve surgery: the SWEDish Multicentre Atrial Fibrillation study (SWEDMAF). Eur Heart J. 2007;28(23):2902-8. https://doi.org/10.1093/eurheartj/ehm378.

145. Bagge L, Probst J, Jensen SM, Blomstrom P, Thelin S, Holmgren A, et al. Quality of life is not improved after mitral valve surgery combined with epicardial left atrial cryoablation as compared with mitral valve surgery alone: a substudy of the double blind randomized SWEDish Multicentre Atrial Fibrillation study (SWEDMAF). Europace. 2017. https://doi.org/10.1093/ europace/eux 253 .

146. Windecker S, Kolh P, Alfonso F, Collet JP, Cremer J, Falk V, et al. 2014 ESC/EACTS Guidelines on myocardial revascularization: The Task Force on Myocardial Revascularization of the European Society of Cardiology (ESC) and the European Association for Cardio-Thoracic Surgery (EACTS)Developed with the special contribution of the European Association of Percutaneous Cardiovascular Interventions (EAPCI). Eur Heart J. 2014;35(37):2541-619. https://doi.org/10.1093/eurheartj/ ehu278.

147. Shaefi S, Mittel A, Loberman D, Ramakrishna H. Off-Pump Versus On-Pump Coronary Artery Bypass Grafting-A Systematic Review and Analysis of Clinical Outcomes. J Cardiothorac Vasc Anesth. 2018. https://doi.org/10.1053/j.jvca. 2018.04.012.

148. Almassi GH, Pecsi SA, Collins JF, Shroyer AL, Zenati MA, Grover FL. Predictors and impact of postoperative atrial fibrillation on patients' outcomes: a report from the Randomized On Versus Off Bypass trial. J Thorac Cardiovasc Surg. 2012;143(1): 93-102. https://doi.org/10.1016/j.jtcvs.2011.10.003.

149. Lee JK, Klein GJ, Krahn AD, Yee R, Zarnke K, Simpson C, et al. Rate-control versus conversion strategy in postoperative atrial fibrillation: a prospective, randomized pilot study. Am Heart J. 2000;140(6):871-7. https://doi.org/10.1067/mhj.2000.111104.

150. Kirchhof P, Benussi S, Kotecha D, Ahlsson A, Atar D, Casadei B, et al. 2016 ESC Guidelines for the management of atrial fibrillation developed in collaboration with EACTS. Eur J Cardiothorac Surg. 2016;50(5):e1-e88. https://doi.org/10.1093/ ejcts/ezw313.

151. Gillinov AM, Bagiella E, Moskowitz AJ, Raiten JM, Groh MA, Bowdish ME, et al. Rate Control versus Rhythm Control for Atrial Fibrillation after Cardiac Surgery. N Engl J Med. 2016;374(20): 1911-21. https://doi.org/10.1056/NEJMoa1602002.

152. Afifi A. CTS trials network: Rate control vs rhythm control for atrial fibrillation after cardiac surgery - Do bitter pills have blessed effects? Glob Cardiol Sci Pract. 2016;2016(2):e201615. https:// doi.org/10.21542/gcsp.2016.15.

153. Tisdale JE, Padhi ID, Goldberg AD, Silverman NA, Webb CR, Higgins RS, et al. A randomized, double-blind comparison of intravenous diltiazem and digoxin for atrial fibrillation after coronary artery bypass surgery. Am Heart J. 1998;135(5 Pt 1):739-47.

154. Oral H, Souza JJ, Michaud GF, Knight BP, Goyal R, Strickberger SA, et al. Facilitating transthoracic cardioversion of atrial fibrillation with ibutilide pretreatment. N Engl J Med. 1999;340(24): 1849-54. https://doi.org/10.1056/nejm199906173402401.

155. Kowey PR, Dorian P, Mitchell LB, Pratt CM, Roy D, Schwartz PJ, et al. Vernakalant hydrochloride for the rapid conversion of atrial fibrillation after cardiac surgery: a randomized, double-blind, placebo-controlled trial. Circ Arrhythm Electrophysiol. 2009;2(6):652-9. https://doi.org/10.1161/circep.109.870204.

156. Roy D, Pratt CM, Torp-Pedersen C, Wyse DG, Toft E, Juul-Moller $\mathrm{S}$, et al. Vernakalant hydrochloride for rapid conversion of atrial fibrillation: a phase 3, randomized, placebo-controlled trial. Circulation. 2008;117(12):1518-25. https://doi.org/10.1161/ circulationaha.107.723866.

157. Pratt CM, Roy D, Torp-Pedersen C, Wyse DG, Toft E, Juul-Moller $\mathrm{S}$, et al. Usefulness of vernakalant hydrochloride injection for rapid conversion of atrial fibrillation. Am J Cardiol. 2010;106(9):1277-83. https://doi.org/10.1016/j.amjcard.2010.06. 054.

158. Camm AJ, Capucci A, Hohnloser SH, Torp-Pedersen C, Van Gelder IC, Mangal B, et al. A randomized active-controlled study comparing the efficacy and safety of vernakalant to amiodarone in recent-onset atrial fibrillation. J Am Coll Cardiol. 2011;57(3): 313-21. https://doi.org/10.1016/j.jacc.2010.07.046.

159. Dalyanoglu H, Mehdiani A, Minol JP, Sipahi NF, Aubin H, Boeken $U$, et al. Conversion of atrial fibrillation after cardiosurgical procedures by vernakalant $(\mathrm{R})$ as an atrial repolarization delaying agent (ARDA). Heart Surg Forum. 2018;21(3): E201-e8. https://doi.org/10.1532/hsf.1970.

160. Gage BF, Waterman AD, Shannon W, Boechler M, Rich MW, Radford MJ. Validation of clinical classification schemes for predicting stroke: results from the National Registry of Atrial Fibrillation. Jama. 2001;285(22):2864-70.

161. Pisters R, Lane DA, Nieuwlaat R, de Vos CB, Crijns HJ, Lip GY. A novel user-friendly score (HAS-BLED) to assess 1-year risk of major bleeding in patients with atrial fibrillation: the Euro Heart Survey. Chest. 2010;138(5):1093-100. https://doi.org/10.1378/ chest.10-0134.

162. Fang MC, Go AS, Chang Y, Borowsky LH, Pomernacki NK, Udaltsova $\mathrm{N}$, et al. A new risk scheme to predict warfarinassociated hemorrhage: The ATRIA (Anticoagulation and Risk Factors in Atrial Fibrillation) Study. J Am Coll Cardiol. 2011;58(4):395-401. https://doi.org/10.1016/j.jacc.2011.03.031.

163. Gage BF, Yan Y, Milligan PE, Waterman AD, Culverhouse R, Rich MW, et al. Clinical classification schemes for predicting hemorrhage: results from the National Registry of Atrial Fibrillation (NRAF). Am Heart J. 2006;151(3):713-9. https:// doi.org/10.1016/j.ahj.2005.04.017.

164. Peguero JG, Issa O, Podesta C, Elmahdy HM, Santana O, Lamas GA. Usefulness of the CHA2DS2VASc score to predict postoperative stroke in patients having cardiac surgery independent of 
atrial fibrillation. Am J Cardiol. 2015;115(6):758-62. https://doi. org/10.1016/j.amjcard.2014.12.037.

165. Bosch NA, Cimini J, Walkey AJ. Atrial fibrillation in the ICU. Chest. 2018;154(6):1424-34. https://doi.org/10.1016/j.chest. 2018.03.040.

166. Manning WJ, Silverman DI, Keighley CS, Oettgen P, Douglas PS. Transesophageal echocardiographically facilitated early cardioversion from atrial fibrillation using short-term anticoagulation: final results of a prospective 4.5-year study. J Am Coll Cardiol. 1995;25(6):1354-61. https://doi.org/10.1016/0735-1097(94) 00560-d.

167. Jaber WA, Prior DL, Thamilarasan M, Grimm RA, Thomas JD, Klein AL, et al. Efficacy of anticoagulation in resolving left atrial and left atrial appendage thrombi: A transesophageal echocardiographic study. Am Heart J. 2000;140(1):150-6. https://doi.org/10. 1067/mhj.2000.106648.

168. Sessler DI. Lost in translation: the 2016 John W Severinghaus lecture on translational research. Anesthesiology. 2017;126(6): 995-1004. https://doi.org/10.1097/ALN.0000000000001603.

Publisher's Note Springer Nature remains neutral with regard to jurisdictional claims in published maps and institutional affiliations. 